

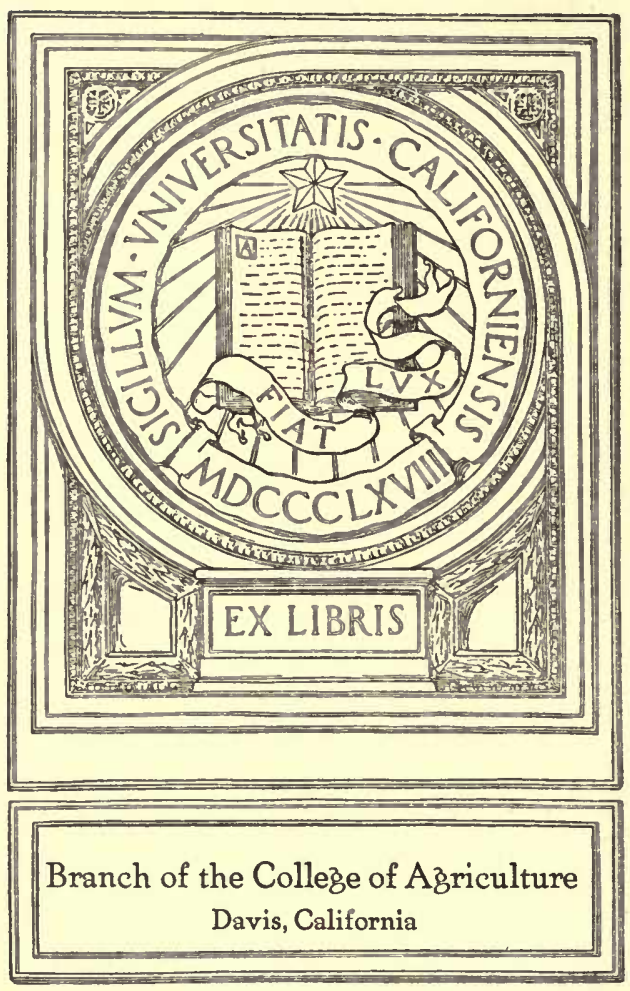




\section{POULTRY LABORATORY MANUAL AND NOTE BOOK}





\title{
POULTRY LABORATORY MANUAL AND NOTE BOOK
}

\author{
PREPARED BY \\ HARRY R. LEWIS, B.S., M.AGR.
}

PROFESSOR OF POULTRY HOSBANDRY, NEW JERSEY STATE COLLEGE OF AGRICULTURE (RUTGERS); POULTRY HUSBANDMAN. NEW JERSEY STATE AGRICULTURAL EXPERIMENT STATION

\section{PHILADELPHIA AND LONDON}

J. B. LIPPINCOTT COMPANY 
Copyright, 1918

By J. B. Lippincott CoMpany

Electrotyped and Printed by J. B. Lippincott Company The Washington Square Press, Philadelphia, U. S. A. 


\section{PREFACE}

This poultry laboratory manual has been planned for use wherever poultry husbandry is taught, whether high school or college. The sequence and distribution of exercises are especially planned to accompany the textbọok, "Productive Poultry Husbandry," published by the J. B. Lippincott Company. Where more than forty-four laboratory periods are available, a number of the exercises are so planned that they can be extended over a greater length of time. On the other hand, where a fewer number of laboratory periods are available certain of the exercises can be omitted or grouped with adjoining ones. The exercises have been planned to occupy laboratory periods having two or more hours to the period.

The equipment necessary to properly perform the exercises outlined is such as would be required on any well-managed poultry farm. Every effort has been made to keep the exercises as practical as possible. These exercises have all been used by the writer in connection with teaching work at the New Jersey State Agricultural College. It is believed that more attention and system to the laboratory method of instruction will greatly increase the fund of information which the student secures from the study of the text.

Although the exercises are arranged to correspond with the text-book above-mentioned, it is not necessary to follow this order. The instructor should frequently glance over the table of contents and select those exercises best suited to the season and to the material available at the time. For example, when disease occurs in a flock, the study of diseases should be assigned. The alert instructor will constantly watch for the most suitable time for each exercise.

Some of the best practice for students is acquired by daily care of stock; both young and mature. They should have the responsibility and practice of caring for incubators, hatching hens, brooder chicks, laying stock, etc. This should include cleaning, feeding, housing, yarding, record-keeping, etc. 


\section{PREFACE}

Such valuable practice may, in many cases, be furnished at the school under the direct supervision of the instructor. Poultry projects carried on by students at home will give more responsibility, and if they are well planned and directed, they will furnish excellent practice. The instructor should supervise home projects from time to time.

Following each exercise, blank spaces are left, in order that this book may be used in part as a note book, and the majority of answers and important notations can be made directly in the book while the laboratory work is in progress. Each student using this manual should be provided with a looseleaf note book of about the same size, in which to make all rough notes, dimensions and miscellaneous facts, and in which to make all mathematical calculations. Such book should be carefully preserved for future reference, or another plan would be to later attach the pages to this manual adjacent to their respective exercises. All final deductions and required facts should be placed neatly in this manual as provided.

New Brunswick, N. J.

HARRY R. LEWIS.

MaRCH, 1918 


\section{CONTENTS}

EXERCISE

PAGE

1. Geographical Distribution of America's Poultry Industry........... 11

2. Locating and Planning the Poultry Farm Lay-out................. 14

3. Distributing the Poultryman's Capital.................... 17

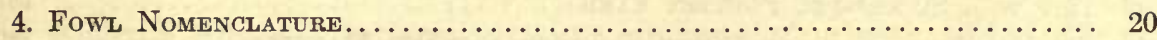

5. Factors Determining the Classification of Fowls.............. 25

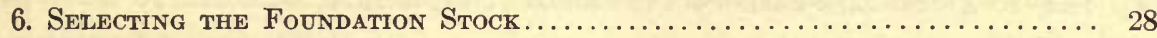

7. Types of Poultry House Construction....................... 31

8. Materials and Methods of Poultry House Construction............ 34

9. Laying out and Leveling the Poultry House Foundation............ 37

10. A Study of Poultry House Fixtures...................... 40

11. A Study of Poultri Yards and Fences.................... 43

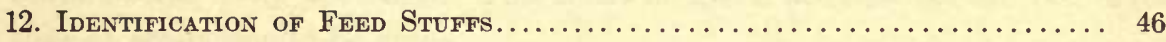

13. Determination of Quality in Ready-mixed Rations............... 49

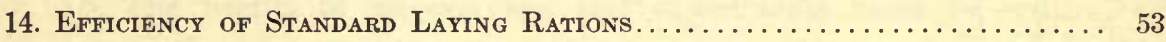

15. Graphic Representation of Modes of Inheritance............. 57

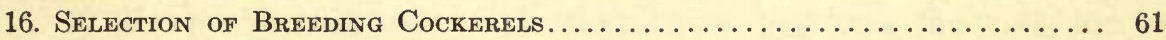

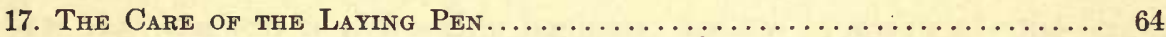

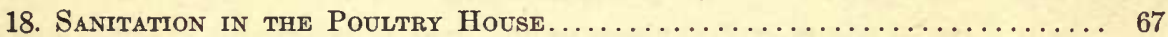

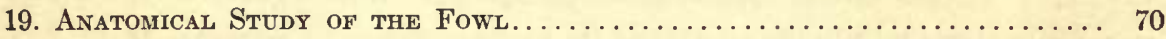

20. The Reproductive System of the Hen.................... 74

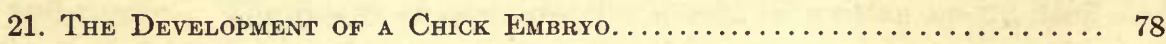

22. The Selection and Care of Hens for Hatching................ 81

23. The Incubator-Location, Construction, and Operation .......... 84

24. The Brooder-Location, Construction, and Operation............. 87

25. A Visit to Young Stock Ranges....................... 90

26. Market Types of Live Poultry......................... 92

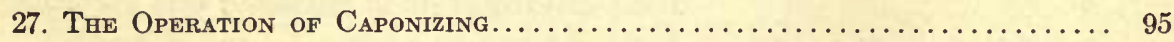

28. Preparing Dressed Poultry for Market.................... 98

29. Preparing Dressed Poultry for Market (Continded) $\ldots \ldots \ldots \ldots \ldots \ldots \ldots$

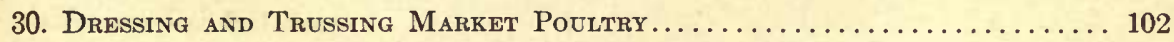

31. Grading and Packing Market Poultry.......................... 104 


\section{CONTENTS}

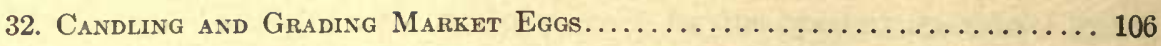

33. The Home Preservation of Eggs in Water Glass................ 109

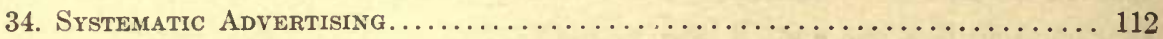

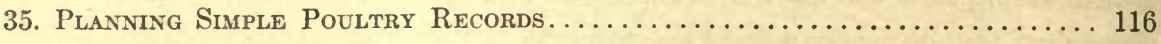

36. Planning Simple Poultry Farm Accounts...................... 118

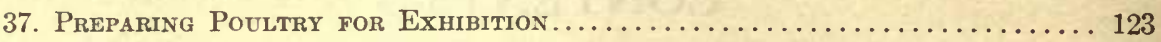

38. Judging Standard-bred Poultry by the Score Card............. 126

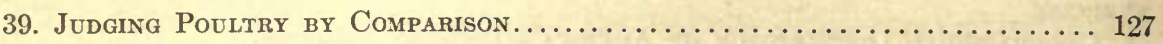

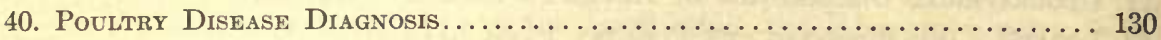

41. Home Preparation and Study of Poultry Medicines.............. 134

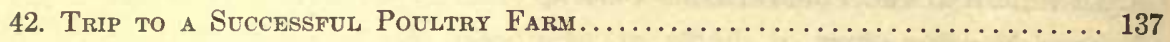

43. Trip to Wholesale and Retail Poultry and EgG Markets............ 140

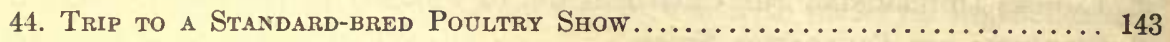




\section{LABORATORY INSTRUCTIONS}

1. Since the exercises are outlined to occupy a definite period of time and since the laboratory periods are distinctly designated, it is important that the student be in his place ready to carry on the work at the appointed time.

2. Every student will be held responsible for unnecessary breakage or loss of apparatus.

3. A schedule will be found posted in the laboratory stating the groups of students who will perform certain exercises during each period when a division of the class is desirable, especially on account of a large amount of work to be accomplished.

4. Exercises which are continuous, over a number of periods, should be distinctly labeled and care taken that apparatus is not disturbed between periods. Many exercises such as chore work, incubation, brooding, etc., require some daily attention. This must be given as required and credit for time so spent should be given.

5. The results of all exercises and experiments must be written up promptly after each laboratory period.

6. Read over each exercise carefully before beginning the work and be sure that the text is thoroughly familiar. Failure to appreciate the object and mode of procedure is very apt to mean failure in the work.

7. All answers to questions and all notations should be made clear, neat and concise. The report of each exercise should be written up by itself and the conclusions neatly and carefully arranged.

8. All exercises should be carried on as outlined, as quietly as is possible, with accuracy, and with a complete understanding of the work. When the work is complete each student or group of students is responsible for the cleaning and replacing of all apparatus used.

9. Access to poultry texts, which can be used as reference work in connection with these laboratory exercises, will be found very useful. Such a reference list follows: 


\section{LABORATORY INSTRUCTIONS}

Productive Poultry Husbandry, Lewis

Poultry Husbandry, Brown

Poultry Breeding and Management, Dryden

Principles and Practices of Poultry Culture, Robinson

Poultry Production, Lippincott

Poultry Culture, Sanitation and Hygiene, Kaupp

Diseases of Poultry, Pearl

Farm Poultry, Watson
Progressive Poultry Culture, Brigham

American Poultry Culture, Sando

Poultry Breeding, Purvis

Practical Poultry Keeper, Wright

Profitable Poultry Production, Kains

Poultry Keeping, Lewis

Our Domestic Birds, Robinson

American Standard of Perfection, American

Poultry Association 


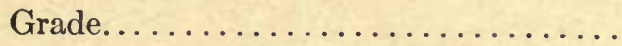

Date.

\section{EXERCISE 1}

\section{GEOGRAPHICAL DISTRIBUTION OF AMERICA'S POULTRY INDUSTRY}

Object.-To study the distribution and centers of production of poultry products in the United States and in certain individual states.

Equipment.-Assorted colored crayons, or red, blue and black ink; a large atlas of the United States and of the individual states that are being studied; complete drafting equipment.

Procedure.-After fastening accompanying maps firmly and properly to drawing board, proceed as follows:

Step.1.-Locate with special colored crayon or ink the large cities and intensive centers of population which are naturally the heavy-consuming centers.

Step 2.- Locate on the map of the United States the specialized centers of production discussed in Productive Poultry Husbandry on page 10, also locate any other districts which are of enough significance to claim distinction. Different colors should be used to designate special egg- and meat-producing centers, also special marks to designate intensive and extensive practices.

Step 3.-Locate in the same manner, as above, all places of importance relating to the poultry industry in the individual state being studied.

Step 4.-Locate in a distinctive manner all large shipping points of poultry products and all important wholesale receiving centers.

Step 5.-Locate by lines the leading transportation routes over which these poultry products must travel to reach the consumer.

Leading Questions.-1. Name the three greatest egg and poultry consuming centers in the United States.

2. Name the states which produce the great bulk of America's eggs, in the order of their importance.

3. Enumerate and give locations and characteristics of three intensive egg-producing centers in the United States.

4. Locate and describe three distinctive meat-producing sections in the United States. 


\section{Exercise 1 (Continued)}

5. What is the relation of the transportation problem and the quality of eggs to intensive vs. extensive production?

6. What do you consider the factors responsible for the prevailing distribution and location of producing centers?

7. What do you consider the trend of future development: a greater intensification near the point of consumption or the reverse? Why?

8. What section of the United States would you personally prefer in which to locate for the development of a commercial poultry farm? Give reasons. 
Exercise 1 (Continued) 
Grade........................

Date.

\section{EXERCISE 2}

\section{LOCATION AND PLANNING THE POULTRY FARM LAY-OUT}

Object.--To study the actual problems incidental to selecting the location for a poultry farm and the laying out of the plant.

Equipment.- Sharpened stakes about two feet long, leveling instrument, compass, a 100-foot tape and a field note book; drafting equipment for plotting the result of the survey.

Procedure.-Take a field trip in company with instructor, studying land contours, drainage, soil conditions, vegetation, etc.

Step 1.-While on field trip, select an area of about five to ten acres which would make a suitable poultry plant.

Step 2.-Locate the boundaries of the specially selected area and drive corner stakes.

Step 3.-Run contour lines with level and tape to determine general slope of land. Let the zero (0) point be some low spot, such as a pond or brook, and from this point lay out approximate contour lines for every five feet of elevation. If the area is very level these lines can be laid out for each foot of elevation.

Step 4.-Make a contour map or plan of the area selected on this accompanying sheet, using the elevation figures secured in step 3 .

Step 5.-Lay out on this map, the areas which should be used for the following parts of the poultry plant: larger head-quarters buildings such as feed houses, incubator and brooder houses, laying houses and yards, ranges for growing stock, and crops.

If time permits, the exact location of the houses and their size can be determined and plotted. If only one period is available, steps 4 and 5 can be omitted.

Leading Questions.- 1 . What factors led to the selection of this particular site chosen?

2. What is the size and shape of the area selected for the development of the plant? 


\section{Exercise 2 (Continued)}

3. Is the site furnished with a natural water supply, if so, how would you make use of it in watering the flocks?

4. What method was used in locating elevations?

5. What point was taken as 0 , and what extreme elevations both plus and minus were encountered?

6. What per cent of the total area was allotted to head-quarters buildings; to laying houses; to ranges; and to crops?

7. What is the capacity and cost of establishing the plant as planned?

8. In your opinion, what are the advantages and disadvantages of this location? 
Exercise 2 (Continued) 


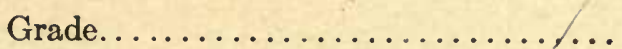

Date.........................

\section{EXERCISE 3}

\section{DISTRIBUTING THE POULTRYMAN'S CAPITAL}

Object.-To determine the proper distribution of capital for the successful management of a poultry farm.

Equipment.-Complete inventories of, at least, five successful poultry farms of different sizes. These inventories can be secured by correspondence, by personal visit, or, if necessary, from previously published data of a similar nature.

Procedure.-Step 1.-Divide the capital, as shown by these inventories, into the following classification:

A. Fixed or invested capital.

1. Land.

2. Buildings.

3. Equipment.

4. Producing stock.

B. Circulating and working capital.

1. Feed.

2. Seed and fertilizers.

3. Supplies.

4. Young stock grown for sale.

5. Money required to pay labor and carry on the business.

Step 2.-Find average distribution of capital on all plants studied.

Step 3.-Express these averages as percentage of total capital invested in different branches, as land, buildings, equipment, stock, feed, labor, etc.

Step 4.-Determine differences, if any, in per cent of distribution of capital on large or small farms, on utility or exhibition farms.

Leading Questions.-1. How many inventories were you able to secure to use in this study? Is this number sufficient to get accurate averages? 


\section{Exercise 3 (Continued)}

Fixed Capital *

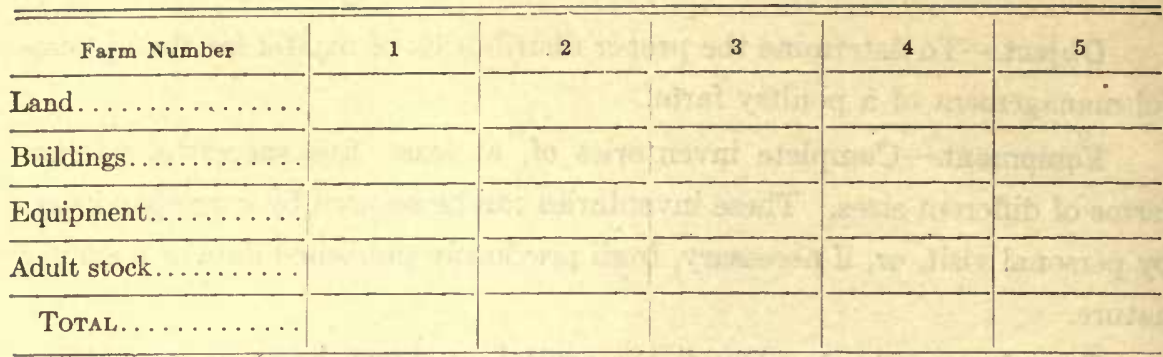

Circulating Capital

\begin{tabular}{l}
\hline Seed, fertilizer........ \\
\hline Supplies.............. \\
\hline Young stock.......... \\
\hline Cash in bank........ \\
\hline Total............ \\
Combined Total...
\end{tabular}

* In these tables use values only.

2. What did you find to be the average cost of land per acre?

3 . What is the average size of farms in acres?

4. What per cent of total capital was invested in fixed capital and what per cent was invested in working capital?

5. What per cent of fixed capital was invested in land, buildings, equipment and stock? Consider each item separately.

6. What per cent of circulating capital was invested in labor, feed and miscellaneous expenses? Consider each item separately.

7. In your opinion, what would be the effect of too great a proportion of fixed capital?

8. What amount of capital would be required per bird on an averagesized poultry farm? 
Exercise 3 (Continued)

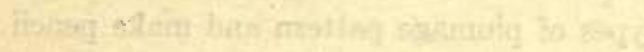

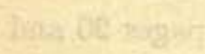

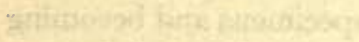

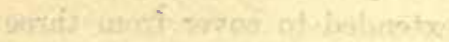

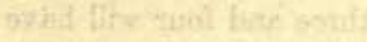

it math omat?

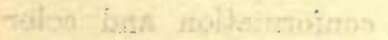

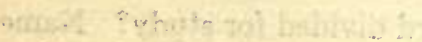


Grade........................

Date

\section{EXERCISE 4}

\section{FOWL NOMENCLATURE}

Object.- To become familiar with the parts of a fowl and common terms used in poultry terminology.

Equipment.-Standard of Perfection, published by American Poultry Association; representative fowls of different breeds and classes; exhibition cages to confine birds, when not being handled.

Procedure.-Step 1.- Handle individually representative birds of each class, locating and studying the characteristics of all parts defined and pictured on pages 18 and 19 of the Standard of Perfection, such as comb, wattles saddle, flights, etc.

Step 2. Study and make pencil sketch of the five standard types of combs, as single, rose, pea, strawberry, and V comb.

Step 3.-Study in detail the parts of a feather and make pencil sketch showing quill, web, vein, barbs and fluff.

Step 4. Study the common types of plumage pattern and make pencil sketch of each, as barred, penciled, laced, spangled, and striped.

Step 5.-Go over the entire glossary of technical terms on pages 20 and 30 of the Standard of Perfection, locating all parts on specimens and becoming so familiar with them that they can be named at sight.

If time will permit, this exercise can be extended to cover from three to five periods, otherwise the drawing work in two, three and four will have to be omitted.

Leading Questions.-1. Name all parts of wings and tail.

2. Into how many parts are the legs and feet divided? Name them in order.

3. Enumerate the important distinctions in conformation and color between males and females.

4. Enumerate five kinds of defective feather markings.

5. Name and describe five common disqualifications.

6. Describe a perfect eye, single comb and barred feather.

7. Into how many important sections is a bird divided for study? Name them. 
Exercise 4 (Continued)

Comb Types 
Exercise 4 (Continued)

Detalls of Feather 
Exercise 4 (Continued)

Detalls of Plumage Pattern 
Exercise 4 (Continued) 


\section{Grade......................... \\ Date. \\ EXERCISE 5 \\ FACTORS DETERMINING THE CLASSIFICATION OF FOWLS}

Object.--To become thoroughly familiar with the Standard, the Utility, and the Breeding classifications of fowls, and the features determining each classification.

NotE.-Breeding classification refers to purity of breeding, as mongrel, cross-bred, pure bred and standard bred.

Equipment.-American Standard of Perfection; representative specimens of as many breeds and varieties as possible, including some mongrel and crossbred individuals.

Procedure.-Step 1.-Separate into groups all fowls belonging to American, Asiatic, Mediterranean, English, and French classes. Make a list of the breeds falling in each group and record all characteristics of shape and color which are peculiar to each group.

Standard Classification of Breeds

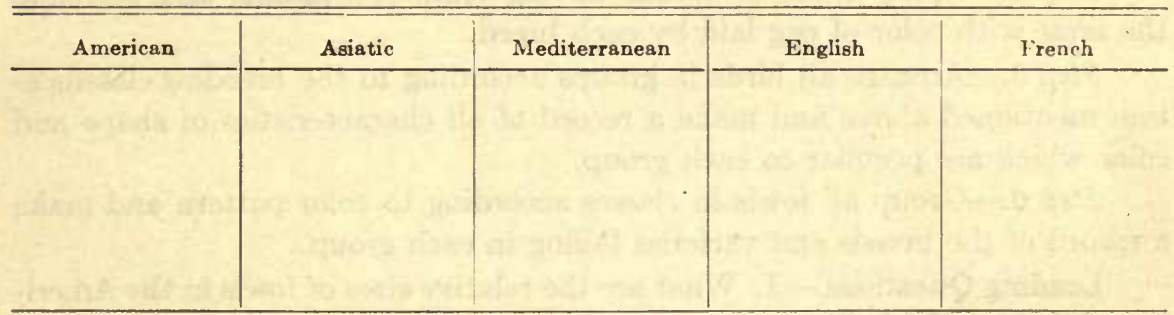

Step 2.-Separate into three groups all fowls which are particularly adapted to the following purposes: (1) egg production, (2) meat production, and (3) both in combination. Make a list of the breeds falling in each group and record all characteristics of color, shape and size which are peculiar to each group.

Utility Classification of Breeds

\begin{tabular}{l|c|c}
\hline \hline Egg Breeds & Meat Breeds & Dual Purpose Breeds \\
\hline & & \\
& & \\
\hline
\end{tabular}




\section{EXercise 5 (Continued)}

Step 3.-Make a list of the ear lobe color of all breeds and correlate the same with color of egg laid by each breed.

Relation of Ear Lobe Colors and Egg Colors

\begin{tabular}{l|l|l|l}
\hline Breed & Ear Lobe Color & Egg Shell Color \\
\hline & & \\
\hline & & \\
\hline & & \\
\hline & & \\
\hline & & \\
\hline & \\
\hline
\end{tabular}

Step 4.-Make a list of breeds having feathered shanks and correlate the same with color of egg laid by each breed.

Step 5.-Arrange all birds in groups according to the breeding classification mentioned above and make a record of all characteristics of shape and color which are peculiar to each group.

Step 6.- Group all fowls in classes according to color pattern and make a record of the breeds and varieties falling in each group.

Leading Questions.-1. What are the relative sizes of fowls in the American, Asiatic and Mediterranean classes.

2. From a study of the specimen fowls at hand, what is the predominating color pattern?

3. From a study of the standard breeds of poultry, as listed in the Standard of Perfection, answer the following points: (a) Number of classes of domestic poultry, not including ducks. (b) Number of breeds of domestic poultry. (c) Number of varieties of domestic poultry. (d) What color pattern occurs the greatest number of times in all standard varieties?

4. Enumerate the breeds which are commonly classed as egg breeds. What are their distinguishing characteristics?

5. Enumerate the breeds which are commonly classed as meat breed. What are their distinguishing characteristics?

6. Enumerate the breeds which are commonly classed as general purpose breeds. What are their distinguishing characteristics?

7. What do you find to be the two most important factors used to classify poultry into certain well-defined groups? 
Exercise 5 (Continued) 
Grade........................

Date........................

\section{EXERCISE 6}

\section{SELECTING THE FOUNDATION STOCK}

Object.-To determine the difference between healthy, vigorous breeding males and females and those which are naturally unfit for breeding purposes.

Equipment.-At least twenty-five yearling hens, and five or more older hens of some common standard breed, representing good and bad breeding specimens; a number of satisfactory coops to confine these birds individually and in groups; at least ten adult cockerels of some common standard breed representing good and bad breeding specimens.

Procedure.-Study carefully these two groups of birds, eliminating all specimens not fit to use for breeding in the following manner:

Step 1.-All birds which show any signs of disease should be discarded and placed in a special cage.

Step 2.-All birds which show extreme age, so as to be unfit for breeders, should be discarded and placed in a separate cage.

Step 3.-All birds which show well defined traits of lack of inherent vigor and stamina should next be discarded and placed in a separate cage.

Step 4.-All specimens which are exceptionally large or too small should next be discarded and placed by themselves in a separate cage; the idea being to leave those which come nearest to standard weight.

Step 5.-From the remaining specimens select approximately ten females and five males which show the best shape and color pattern for the breed being studied. Those selected can well be placed in order of excellence for close study.

Nоте.- If possible this method of elimination and final selection should be practiced with a much larger number of specimens than is suggested above.

Leading Questions.- 1 . Considering the total number of specimens studied, what percentages were eliminated on account of : (1) disease, (2) age, (3) lack of vigor, (4) size, (5) weight, and (6) failing to meet breed and variety requirements of shape and color.

2. What are some of the more prominent diseases which would make yearling hens unfit for breeding?

3. What features would you use in eliminating birds too old for breeding? 


\section{Exercis: 6 (Continued)}

4. What signs of lack of vitality did you find in both males and females?

5. What was the weight of the special breeders finally selected?

6. What, in your estimation, is the value of the specially selected birds, if you were to purchase them for your own use?

Birds Discarded for Different Reasons

Make an $\mathrm{X}$ in proper column opposite band number

\begin{tabular}{|c|c|c|c|c|c|c|}
\hline Band No. & Disease & Age & Lack of Vigor & Size & Type & Color \\
\hline & 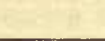 & & & & & \\
\hline & & & & & & \\
\hline & & & - & & & \\
\hline & & 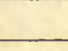 & $\therefore$ & & & \\
\hline & & & & & & \\
\hline & & & & & & \\
\hline & & & & & & \\
\hline 2 & & & 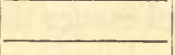 & & 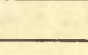 & \\
\hline & & & & & & \\
\hline & & & & & & \\
\hline & & & & & & \\
\hline & & & & & & \\
\hline & & & & & & , \\
\hline ne & 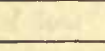 & & & & & \\
\hline & & & & & & \\
\hline & & & & L & & \\
\hline & & & & & & \\
\hline & & & & & & \\
\hline & & & & & & \\
\hline & & & & & & \\
\hline & & & & & & \\
\hline 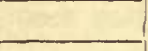 & & & & & & \\
\hline+ & & & & & & \\
\hline 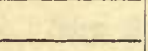 & & & & & & \\
\hline & & & & & & \\
\hline Totals... & & & & & & \\
\hline
\end{tabular}


Exercise 6 (Continued) 


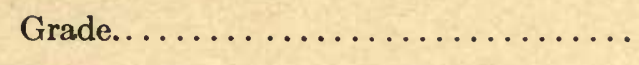

Date

\section{EXERCISE 7}

\section{TYPES OF POULTRY HOUSE CONSTRUCTION}

Object.-To determine the efficiency of various types and styles of poultry houses.

Equipment.-Access to various types and sizes of poultry houses, especially shed-roof, gable-roof, and half monitor roof houses; also large- and small-flock houses; one 50-foot tape measuring in feet; one two-foot rule.

Procedure.-Make a trip of inspection about the poultry plant, studying all types of houses available and determining the following points:

Step 1. - Study the design, arrangement, construction and uses of the following types of roofs: shed, two-third-span, monitor, half-monitor, and A-coop. Determine the advantages and disadvantages of each.

NoTE.-If these types are not all available others may be substituted.

Step 2.-Measure a typical roof of each of the above types and determine the area of roof in proportion to each square foot of floor space which it covers.

Proportion of Roof to Floor Covered

\begin{tabular}{|c|c|c|c|c|c|c|}
\hline House Type & Shed & Gable & $\begin{array}{c}\text { Two-thirds- } \\
\text { Span }\end{array}$ & Monitor & $\underset{\text { Monitor }}{\text { Half- }}$ & $\mathbf{A}$ \\
\hline $\begin{array}{l}\text { Square feet of roof to cover } \\
1 \text { square foot of floor }\end{array}$ & & & & & & \\
\hline
\end{tabular}

Step 3.-Determine the relative amounts of material required to construct each of these roof types.

Step 4.- Study the method of construction and determine the relative amounts of labor required to frame and build each type.

Step 5.-Take the dimensions of a number of laying houses, some long houses and some small-flock houses. Determine the relation between wall area and floor area in each size.

Step 6.-By figuring the amount of material required, determine the advantages of a double-pen laying house over two single-pen houses, the latter with a combined capacity equal to the double-pen house. 


\section{Exercise 7 (Continued)}

Leading Questions.-1. What is the best roof type and why?

2. Where can a half-monitor be used to advantage?

3. What is the difference in amount of lumber, required to build a shed roof, a two-thirds-span roof and an A-roof all over the same floor area?

4. How does the distance around the outside wall of a house vary with the shape of the house?

5. What is the determining feature in planning the height of a laying house?

6. What are the advantages in adopting a standard unit laying house?

7. Describe what you consider to be an ideal laying house for 100 birds? 


\section{Exercise 7 (Continued)}


Grade.........................

Date.

\section{EXERCISE 8}

\section{MATERIALS AND METHODS OF POULTRY HOUSE CONSTRUCTION}

Object.-To become thoroughly familiar with materials used and methods followed in framing and constructing laying houses.

Equipment.-Access to a number of typical and efficient poultry houses; a two-foot rule.

Procedure.-Make an inspection trip, visiting each house to be studied, observing the following features:

Step 1.-Before entering the house determine size, shape and style of roof and material used for outside wall and roof.

Step 2.-Determine the kind of material used for foundation and floor construction and note the details of construction.

Step 3.-Upon entering the house note the location, size and materials used for sills, posts, studding, plate and rafters. Note distances between studding and rafters.

Step 4.-Determine the amount of glass and muslin in the front wall. Express each in relation to 100 square feet of floor space.

Relation of Glass and Muslin to Floor Space

\begin{tabular}{l|c|c|c|c|c}
\hline House No. & $\begin{array}{c}\text { Square Feet } \\
\text { Floor Space }\end{array}$ & $\begin{array}{c}\text { Square Feet } \\
\text { Glass }\end{array}$ & $\begin{array}{c}\text { Square Feet } \\
\text { Muslin }\end{array}$ & $\begin{array}{c}\text { Square Feet of } \\
\text { Glass to } 1 \\
\text { Square Foot Floor }\end{array}$ & $\begin{array}{c}\text { Square Feet of } \\
\text { Muslin to } 1\end{array}$ \\
\hline & & & & & \\
\hline & & & & & \\
\hline Square Foot Floor
\end{tabular}

Step 5.- Study any special method of ventilation provided and determine by the use of smoke or feathers the air currents which are set up in the house. 


\section{Exercise 8 (Continued)}

Step 6.-Study special methods of supporting roof in deep houses.

Step 7.-Compare the differences in amount of studding needed where outside boarding, such as novelty siding, is used or where tongued and grooved boards, such as roofers, are used.

Leading Questions.-1. Which do you find makes the most economical and efficient construction for outside walls; novelty siding or roofers covered with roofing paper?

2. What do you consider the best materials for foundation and floors? Would you make any exception to your answer?

3. Name the sizes of lumber which should be used for the sills, posts, plates, studding and rafters?

4. What kinds of lumber are generally used for framing the poultry house?

5. How far apart are rafters and studding? What factors, if any, affect these distances?

6. How many square feet of muslin openings should there be to every 100 square feet of floor space?

7. How many square feet of glass should there be to every 100 square feet of floor space?

8. What do you consider the most important type of ventilation for the poultry house?

9. How should the poultry house be fastened to the foundation and why is this factor so important? 
Exercise 8 (Continued) 
Grade....................

Date

\section{EXERCISE 9}

\section{LAYING OUT AND LEVELING THE POULTRY HOUSE FOUNDATION}

Object.-To study the proper method of determining the exact location for the poultry house and the best method of laying out a foundation for the same.

Equipment.-Wood stakes, hatchet, two-foot rule, mason's cord, spirit level, and, if possible, a surveyor's level.

Procedure.-Make a field trip to some suitable location, preferably the area surveyed in Exercise 2, and proceed as follows:

Step 1. - Select the kest location for the long laying house, if it has not already been done in Exercise 2. Consider contour, drainage, vegetation, grading, yard room, etc. Drive four stakes to approximately mark the four corners of the house on the site selected.

Step 2.- Lay out foundation lines, erect batten boards and stretch trench lines according to method described on pages 124 and 125 in Productive Poultry Husbandry.

Step 3.- It is frequently found desirable to lay out trench lines quickly, paying no attention to levels until after the foundation trench is dug, after which grading stakes can be leveled at the time the finished wall is leveled. Two methods can be followed depending upon equipment available. If only a carpenter's spirit level is available proceed as follows: Determine level at which it is desirable to finish foundation wall. Drive stake at this level at approximately the center of the house. From this stake by means of a leveling board, spirit level and temporary stakes run level lines to the four corners, driving permanent stakes at each corner and marking correct level on each. When constructing concrete forms for walls they can be leveled to these stakes. In determining the level of the wall it should be the plan to have it at all points at least six inches above the ground line at that point. If the ground is sloping this may mean considerable grading or an excessive height at some points. 


\section{EXERCISE 9 (Continued)}

Step 4.-When a surveyor's level is available it will be found very easy to locate the proper levels at the different points in the foundation wall by setting the level at the leveling stake in the center of the house area and from this point sighting with leveling pole on the various points where levels are to be marked. Follow this method on another location or use this method to check the work in step 3.

Leading Questions.-1. How large a house did you locate and lay out?

2. What special features led to the selection of the site chosen?

3. Explain the use of the 6-8-10 right-angle triangle in laying out foundation lines.

4. What are batten boards and how and where are they placed?

5. In what direction did you face the poultry house and why?

6. In using leveling board and spirit level how did you avoid any possible inaccuracy of leveling board?

7. How can you test foundation levels by the use of the same instruments after they are once determined?

8. In using the surveyor's level what errors did you find in former work?

Note.-If time permits, one or more exercises should be given at which the students should construct themselves a portable young stock colony house. For plans and styles see Productive Poultry Husbandry, pages 141, 354, and 373. 
Exercise 9 (Continued) 
Grade.

Date.

\section{EXERCISE 10}

\section{A STUDY OF POULTRY HOUSE FIXTURES}

Object.-To study the construction and arrangement of poultry house fixtures and to determine their efficiency.

Equipment.-Access to a number of laying houses in which different types of equipment are in actual use.

Procedure.-Make an inspection trip to the poultry houses, observing the following:

Step 1.-Determine the capacity of the house for the breed kept.

Step 2.-Measure the area of dropping boards and note their height, location and manner of construction.

Step 3.-Determine total linear feet of perches. Note arrangement of perches. Determine perch room per bird.

Step 4.- Note size, construction and arrangement of nests. Determine number of nests in proportion to number of birds. If trap nests are available make special study of design and apparent efficiency.

Poultry House Equipment

\begin{tabular}{l|l|l|l|l|l}
\hline \multicolumn{1}{c|}{ House No. } & Floor Area & Capacity & $\begin{array}{c}\text { Square Feet } \\
\text { Dropping } \\
\text { Board }\end{array}$ & $\begin{array}{c}\text { Linear } \\
\text { Feet } \\
\text { Perch }\end{array}$ & $\begin{array}{l}\text { Number } \\
\text { of Nests }\end{array}$ \\
\hline & & & & & \\
\hline & & & & & \\
\hline
\end{tabular}

Step 5.-Note presence and arrangement of broody coops. Determine size of coops in relation to number of birds and breed. 


\section{Exercise 10 (Continued)}

Step 6.-Determine the method of providing dust wallows and note the size of wallows in relation to the size of the house.

Step 7.- Study style, construction and arrangement of mash hoppers. Determine their efficiency.

Step 8.- Note style and arrangement of water vessels.

NoTE.-Take complete notes on all observations and determine efficiency of each equipment studied.

Leading Questions.- 1 . Where are the roosts and dropping boards generally placed and why?

2. What materials are used for roosts?

3. What would you give as a rule for the amount of roost room?

4. If dropping boards are not used what takes their place?

5. What are the sizes and number of nests and where are they located?

6. Do you prefer home made to commercial hoppers? If so under what condition and why?

7. Where should the dust wallow be located and why?

8. Describe a convenient and efficient method of providing water. 
Exercise 10 (Continued) 
- Grade.....................

Date

EXERCISE 11

\section{A STUDY OF POULTRY YARDS AND FENCES}

Object.-To determine the best arrangement of yards and proper fence construction.

Equipment.-Access to one or more poultry plants where different types of fences and yarding systems are in use; a fifty-foot tape.

Procedure.-Step 1. Study the shape and arrangement of yard. Note whether single or double; if double, note arrangement whether both front yards or one front and one back.

Step 2.-Determine size of yard in square feet. Determine number of birds having access to yard. Determine area of yard allowed per bird. Note how this varies with double and single yard.

Poultry Yards

\begin{tabular}{l|l|l|l|l}
\hline Yard No. & Area & $\begin{array}{c}\text { Birds Running } \\
\text { in Yard }\end{array}$ & $\begin{array}{c}\text { Condition } \\
\text { of Yard }\end{array}$ & $\begin{array}{c}\text { Square Feet of } \\
\text { Yard Per Bird }\end{array}$ \\
\hline & & & & \\
\hline & & & & \\
\hline & & & & \\
\hline
\end{tabular}

Step 3.-Observe crops growing in yard and inquire the nature of any crop rotation which may be practiced to insure continuous greens.

Step 4.-By comparing yards of different shapes and areas determine which yard is the most economical to fence, a long narrow yard or a square yard.

Step 5.-Study the details of fence construction, observing height, kind of wire, condition of wire, number of strands of wire, method of fastening at 


\section{Exercise 11 (Continued)}

ground and method of fastening to posts and ground. Observe distance between posts, method of bracing corner posts and kinds of posts.

Step 6.-Study the size, location and method of construction of gates.

Leading Questions. - 1 . What are the advantages of a double over a single yard?

2. From your observation what type of double yard do you consider the best.

3. How much yard room should be allowed for each 100 birds, first, where only single yards are used and, secondly, where double yards are used.

4. Outline a simple rotation for green cropping double yards.

5 . What shape of yards would you build if possible?

6. How far apart should poultry fence posts be placed?

7. What style of fence construction did you find to be most desirable?

8. What are the advantages in building poultry fence in two widths of wire?

9. What should be the determining feature in planning the location of gates? 


\section{Exercise 11 (Continued)}




\section{IDENTIFICATION OF FEED STUFFS}

Object.-To become thoroughly familiar with all poultry feeding stuffs, both as to appearance and quality.

Equipment.-Pint samples of all common poultry feeds, paper pie plates, torsion balance weighing in grams, $17.5 \mathrm{cc}$. acid measuring glass and a pen knife.

Procedure.-Each sample of whole grain should be studied for the following features: size, color, shape, hardness, proportion of husk or shuck, uniformity of grains in sample, purity.

Step 1.-To determine the relative size of different grains, the number required to fill a $17.5 \mathrm{cc}$. measuring glass should be taken. Wheat should be expressed as one and all other grains expressed in terms of wheat. Example: suppose 100 wheat kernels are required to make $17.5 \mathrm{cc}$. in volume and wheat is represented in our standard by 1 , then if it requires 200 kernels of kafir corn to make the same volume, its size would make and be expressed as .5 or $1 / 2$, meaning that the kernels were half as large as wheat. If it took, on the other hand, 50 kernels of corn its size would be expressed as 2, meaning that the kernels were twice the size of wheat.

Step 2.-Designate color by comparison with other grains of somewhat the same color; as, wheat is brown, slightly lighter in shade than rye, etc.

Step 3.-In designating shape of kernels describe and make sketch of each and liken, where possible, to some common object, as spherical, cylindrical, kidney shape, etc. and soft.

Step 4.-Designate hardness by grading into groups of hard, medium

Step 5.-State whether kernel has loose fibrous shuck, such as oats, or a hard covering, as corn.

Step 6.-Observe whether grains in sample are uniform as to quality or not.

Step 7.-Separate any foreign materials; determine amount and character of the same.

Step 8.- Study each sample of ground grain for the following features: color, texture, uniformity and purity.

NoTE.-Study each sample in comparison with other samples in order 46 


\section{EXercise 12 (Continued)}

Descriptions of Grains

\begin{tabular}{|c|c|c|c|c|c|c|c|}
\hline Grain & Size & Shape & Color & Hardness & Shuck & Uniformity & $\begin{array}{l}\text { Foreign } \\
\text { Material }\end{array}$ \\
\hline & & & . & & & & \\
\hline & & & & & & & \\
\hline & & 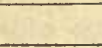 & & & & & \\
\hline & & 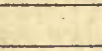 & & 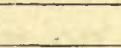 & & & \\
\hline & & & & & & & \\
\hline & & & & & & & \\
\hline & & & & & & & \\
\hline & & & & & & & \\
\hline & & 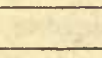 & +2 & & & & \\
\hline OTALS & & $-\infty$ & & & & & \\
\hline
\end{tabular}

that complete identification can be made possible. If time permits, this exercise can well be extended over two or more periods.

Leading Questions.- 1 . What are the relative comparisons in size of kernels between corn, wheat, rye, oats, barley, kafir and millet?

2. What are the distinguishing colors of barley, wheat, buckwheat and peas?

3. Describe the relative shapes of wheat and rye kernels?

4. Compare the relative hardness of soy beans, corn and oats?

5. Name five grains having a large amount of shuck or husk?

6. What impurities did you find in the wheat?

7. How would you distinguish between wheat middlings, oil meal and buckwheat middlings.

8. How would you distinguish between meat scrap, fish scrap and digester tankage? 
EXERCISE 12 (Continued) 
Grade

Date.

EXERCISE 13

\section{DETERMINATION OF QUALITY IN READY-MIXED RATIONS}

Object.-To be able to determine the ingredients in ready-mixed rations, both as to quality and quantity, and to determine the general efficiency of such mixtures.

Equipment.-Pound samples of a number of grain rations, paper pie plates, torsion balance weighing in grams, pen knife.

Procedure.-Study each ration separately in the following manner:

Step 1. - Weigh out a 25 gram sample of each ration as it is needed for study. At other times keep sample in a dry, air tight container.

Step 2.- Spread sample out on white paper and by use of pen knife separate the sample into its component parts, such as wheat, oats, barley, etc.

Step 3.-Weigh each ingredient separately and reduce the amount of each to percentage of the whole by multiplying its weight by 4 .

Step 4. Study the quality of each ingredient and record any poor quality feed or adulterations.

Form for Studying Rations

Name of ration.

\begin{tabular}{|c|c|c|c|c|c|c|c|}
\hline \multirow{2}{*}{$\begin{array}{l}\text { Ingredients } \\
\text { Found }\end{array}$} & \multirow[b]{2}{*}{ Weight } & \multirow[b]{2}{*}{ Quality } & \multirow{2}{*}{$\begin{array}{l}\text { Per Cent } \\
\text { of Whole }\end{array}$} & \multirow{2}{*}{$\begin{array}{l}\text { Market } \\
\text { Valuo }\end{array}$} & \multicolumn{3}{|c|}{ Nutritive Valuen } \\
\hline & & & & & $\begin{array}{l}\text { Pro- } \\
\text { tein }\end{array}$ & $\left|\begin{array}{c}\text { Carbo- } \\
\text { hydrate }\end{array}\right|$ & Fat \\
\hline & & & & & & & \\
\hline & & & & & & & \\
\hline & & & & & & & \\
\hline & & & & & & & \\
\hline & & & & + & _. & & \\
\hline & t & 25 & 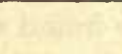 & 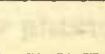 & 2 & V & \\
\hline & & & & 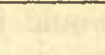 & & & \\
\hline OTALS & & & & & & & \\
\hline
\end{tabular}




\section{Exercise 13 (Continued)}

Step 5.-By applying the prevailing market prices for each individual ingredient determine the cost of mixing the ration at home by buying locally the grains needed. How does this price compare with the price of the commercial mixture?

Step 6.-Determine the amount of nutrients in 100 pounds of the mixture by applying nutritive values found in Table XVIII in Productive Poultry Husbandry, page 518.

Step 7.-Arrange rations studied in the order of their efficiency, considering quality of ingredients, proportion of ingredients, and cost of mixture.

Step 8.- - Investigate and compare the standing of each ration studied by comparison of these results with those secured by Experiment Station Analysis. Experiment station feeding stuffs bulletins will give these figures.

NoтE.- The same procedure as above can be followed with dry mash mixtures, except it will be impossible to accurately determine the exact amount of each ingredient.

Leading Questions.- 1 . What were the most common poultry grains used in mixed scratch rations?

2. What was the average per cent of protein found in grain rations?

3 . What variations in nutritive ratio were found in grain rations?

4. What should be the average cost of 100 pounds of a good poultry scratch feed?

5. If you were to purchase a commercial poultry scratch feed, name three brands which you would consider.

6. In what nutrient, if any, did the rations most often fall below guarantee?

7. How many rations fell below guarantee?

8. What adulterants were found and why were they used?

9. In general would it be more economical to buy commercial readymixed rations or mix them at home?

10. In step 3 , why do you multiply the weight by 4 ? 
Exercise 13 (Continued) 
Exercise 13 (Continued) 
Grade ........................

Date.

\section{EXERCISE 14}

\section{EFFICIENCY OF STANDARD LAYING RATIONS}

Object.-To determine the efficiency of certain recommended complete rations for laying hens.

Equipment.-Detailed composition of certain rations, especially those recommended by experiment stations and those used by successful poultrymen. This information should include ingredients of grain ration and dry mash ration, together with amounts and time of feeding, and also any modifications of this ration for different breeds in different seasons, also any supplemental feeds given, such as sprouted oats or beets.

Procedure.-Study each complete ration in detail according to the following procedure:

Step 1.-By using table of nutrients on page 518, in Productive Poultry Husbandry, determine the amount and ratio of the nutrients in the dry mash ration.

Step 2.-By the use of the same table determine amount and proportion of nutrients in the scratch grain ration.

Step 3.-Combine these two rations in the proportion in which they are fed and determine the amount and proportion of nutrients consumed by 100 hens in a day.

Step 4.--Determine how the result compares with the Wheeler standard for laying hens. (Productive Poultry Husbandry, page 175).

Step 5.-Using local current prices for poultry feeds, determine the cost of this complete ration and the cost of feeding 100 birds per day.

Step 6.-Determine the cost of feeding one hen for one year on the basis of these formulas.

Step 7.-Group results of all rations studied and arrange the rations in the order of their efficiency, considering proportion of ingredients, nutritive ratio and cost.

Notz.-For ease in figuring nutritive values the total weight of each ration studied should be taken as one hundred pounds.

Leading Questions.-1. What ingredients were most universally used in the dry mash rations?

2. What ingredients were most generally used in the scratch grain rations?

3. What should constitute the average daily diet of 100 hens in protein, carbohydrates and fat? Correlate your results with this standard. 


\section{Exercise 14 (Continued)}

Composition of Dry Mash

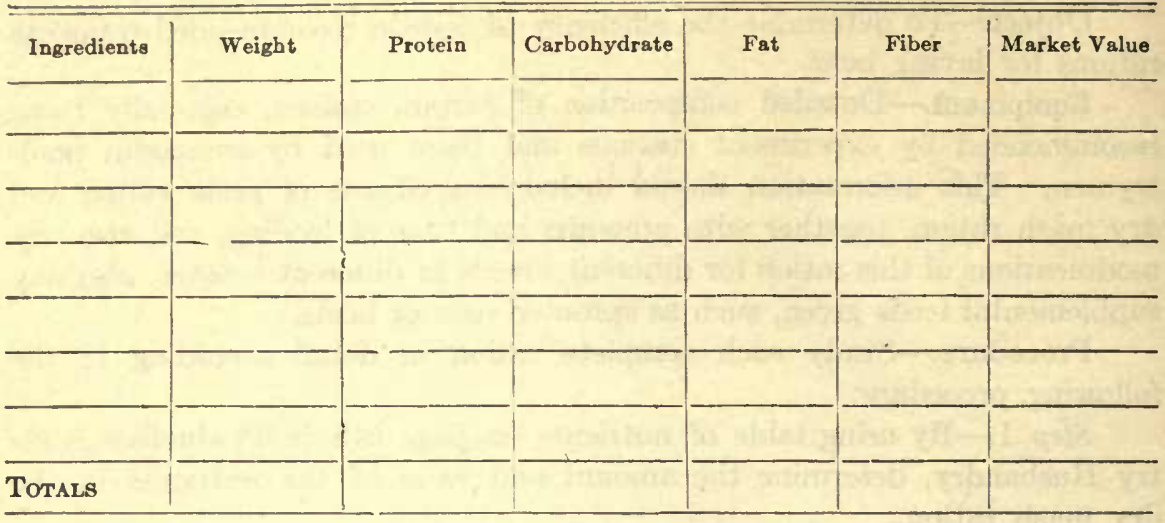

Scratch Grain Ration

\begin{tabular}{l|l|l|l|l|l|l}
\hline Ingredients & Weight & Protein & Carbohydrate & Fat & Fiber & Market Value \\
\hline & & & & & & \\
\hline & & & & & & \\
\hline & & & & & & \\
\hline & & & & & & \\
\hline
\end{tabular}

Combined Totals in Proportion to the Amount of Each Ration Consumed

Totals

4. What do you find the average cost of feeding 100 laying hens per day?

5. How much does it cost, on the average, to feed one hen a year?

6. Assuming ten dozen eggs to be the production, what will be the food cost of one dozen eggs?

7. Give a detailed ration which, from this study, you consider the most efficient and economical.

8. Do you notice any systematic variation in the rations studied, which might be caused by latitude and climatic conditions? 
Exercise 14 (Continued) 
Exercise 14 (Continued) 
Grade........................

Date.

\section{EXERCISE 15}

\section{GRAPHIC REPRESENTATION OF MODES OF INHERITANCE}

Object.-To become familiar with methods of representing graphically certain fundamental principles of inheritance.

Equipment.-Drafting ink, red and black; lettering pen; facts concerning the mode of inheritance of certain well defined characters; as, comb character, plumage pattern, shank feathering, shank color, beak color, fifth toe, etc.

Procedure.-Designate the inheritance of certain characters through the F1 and F2 generations on the following diagrams.

Step 1.-On the following diagrams plot at least three pairs of contrasted characters without paying any attention to the question of dominance.

Note.-See Productive Poultry Husbandry, pages 231 to 234, for explanation of this and the following laws.

The First Phase of Mendel's Law

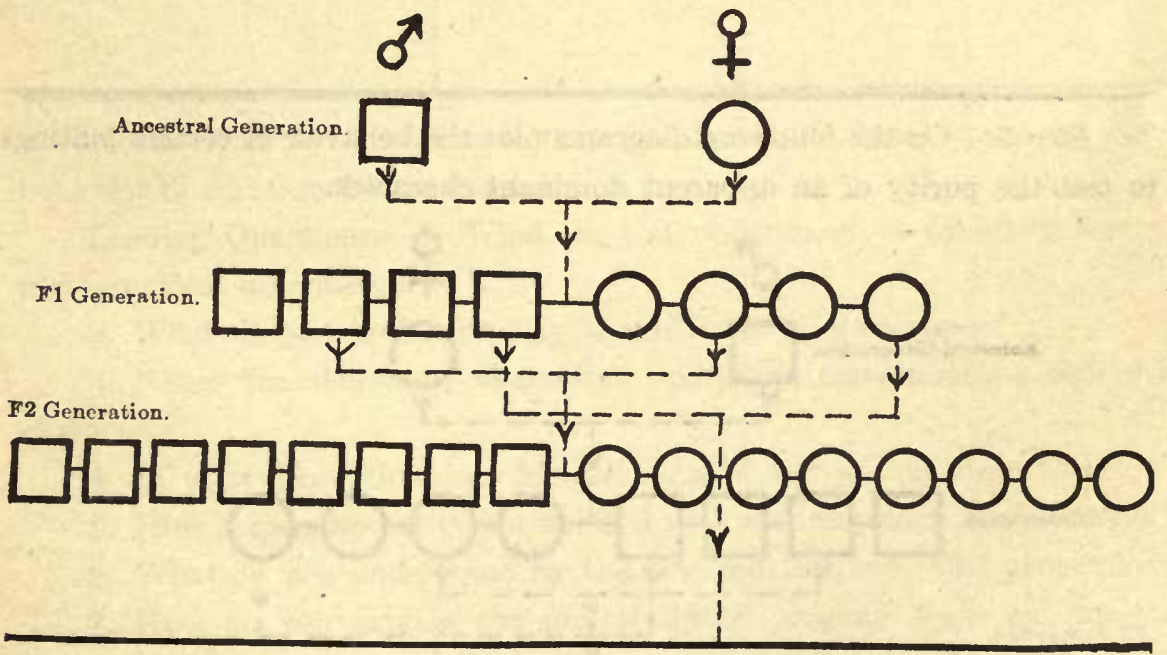




\section{EXERCISE 15 (Continued)}

Step 2.-On the following diagrams plot the same contrasted characters showing the effect of dominance upon the appearance of the progeny.

The Second Phase of Mendel's Law

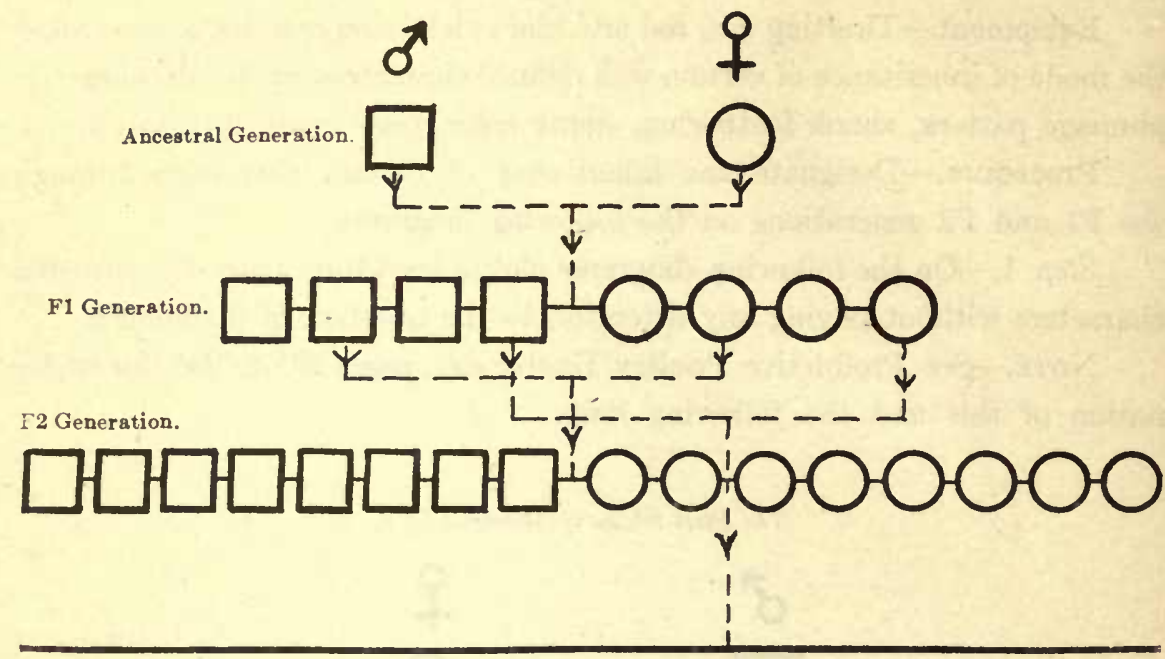

Step 3.-On the following diagrams plot the behavior of certain matings to test the purity of an apparent dominant character.

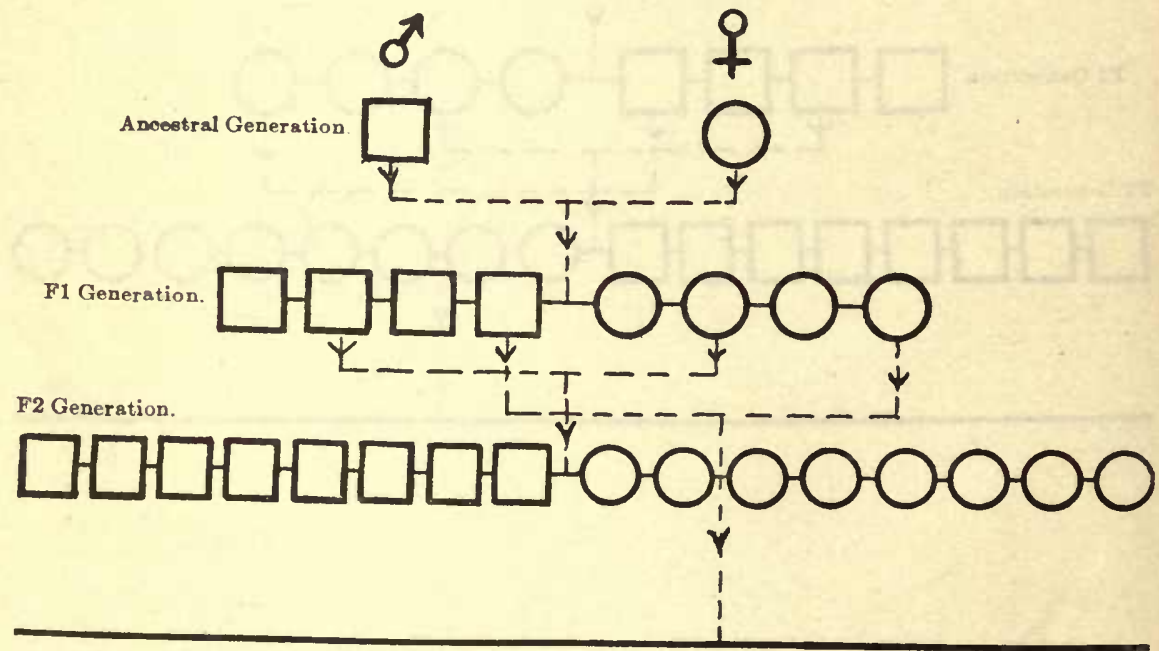




\section{EXercise 15 (Continued)}

Step 4.-Plot on the following diagram at least two characters which are sex-linked in their mode of inheritance.

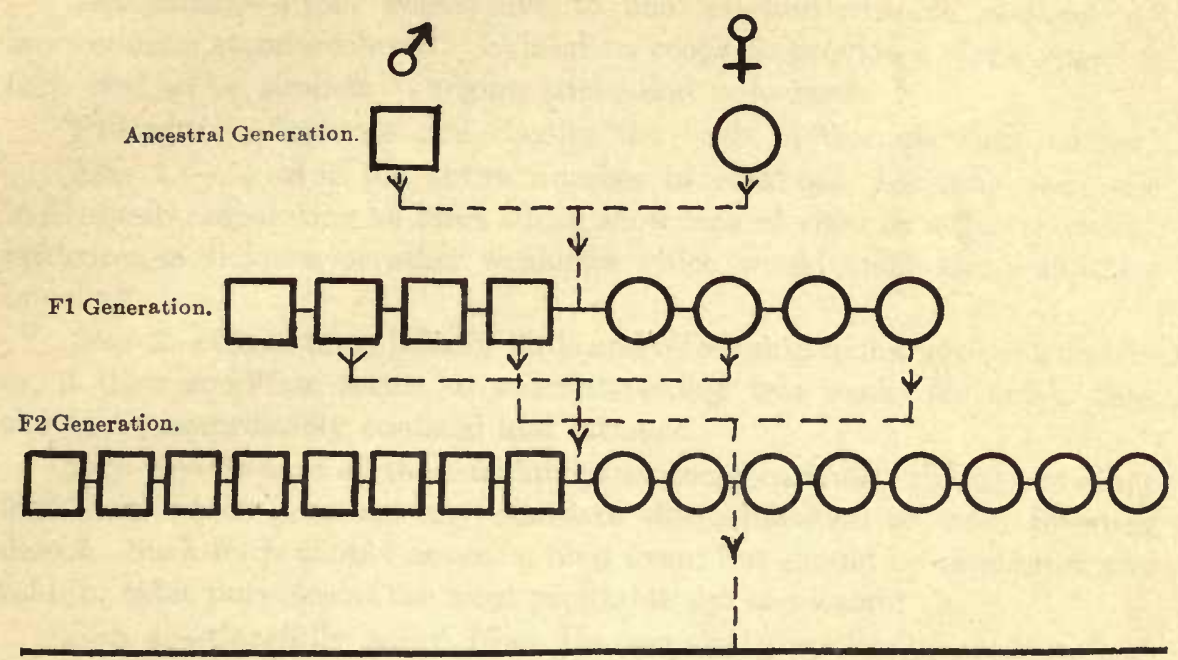

Note-Additional diagrams may be drawn on blank page to show behavior of additional characters.

Leading Questions.-1. What do you understand as Mendel's law of mathematical inheritance?

2. What do you understand as Mendel's law of dominance?

3. Name ten dominant characters and their corresponding recessive characters?

4. In what generation does Mendel's law of segregation begin to act?

5. How is gametic purity harmonized with an analysis of Mendel's law?

6. What do you understand by the 1 st, 2 nd, 3rd, etc., filial generation?

7. How do you explain the uniformity of progeny from an original cross, and the great variability of progeny of future generations from this cross?

8. Enumerate the commercial possibilities from an understanding of sex-controlled inheritance. 
Exercise 15 (Continued)

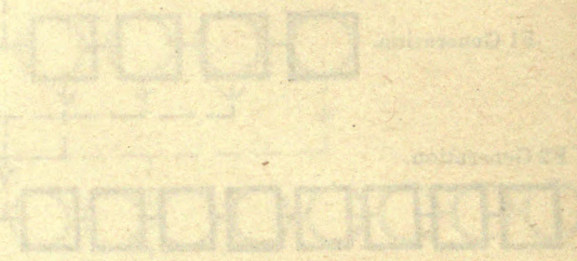

60 


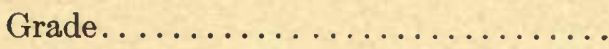

Date.

\section{EXERCISE 16}

\section{SELECTION OF BREEDING COCKERELS}

Object.-To study an efficient and simple method of culling and selecting cockerels desirable to use for breeding.

Equipment.-From twenty-five to one hundred suitable cockerels of any common standard breed. Exhibition coops to provide a single cage for each bird to be studied. Judging sticks and note book.

Procedure.-Separate and classify the birds in the following manner:

Step 1.-Go over the entire number of cockerels, handling each one individually, separating all birds which show lack of vigor or which show any evidences of sickness or other weakness which would make them unfit for breeding.

Step 2.-Crate these inferior birds and either ship to market immediately or, if their condition seems to warrant feeding two weeks for finish, they should be immediately confined and fattened.

Step 3.-Go over all the remaining specimens carefully, culling out every individual which possesses any standard disqualification or other breeding defect. Such birds should never be bred from, but should be eliminated and sold for table purposes at the most profitable age and weight.

Step 4.-Carefully select from the remaining specimens the ten best birds, placing them in separate cages by themselves. Consider in this final selection, body conformation, plumage pattern, vigor and general breeding ability.

Step 5.-Judge these specially selected birds by comparison, placing them in the order of their excellence on the basis of their probable breeding ability.

NoтE.-Where but a limited number of cages are available the birds can be handled according to the above plan in groups and the best of each group finally brought together for last comparison judging.

Leading Questions. - 1 . What per cent of the birds examined did you find deficient on account of each of the following factors? (a) Lack of vigor (b) Disease........ (c) Disqualifications.......

2. Describe the special features possessed by the first and second bird selected:

3. What per cent of the flock did you consider suitable for breeding? 
Exercise 16 (Continued)

Judgment on Cockerels for Breeding

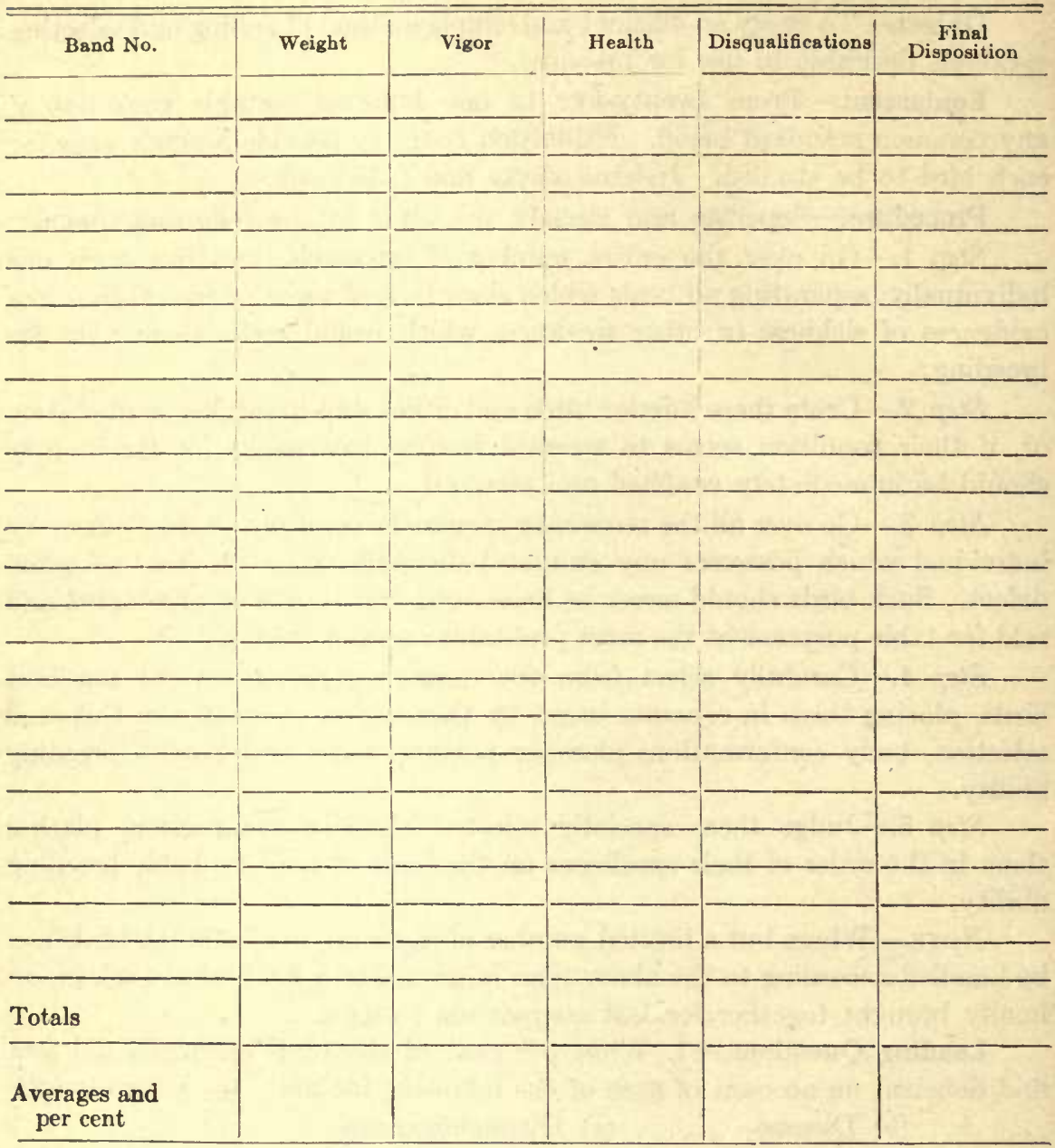

4. What would you consider the greatest relative importance in selecting the breeders, plumage pattern or body conformation?

5. What is the practical commercial application of this exercise?

6. What is the best time of year to select the breeding cockerels and how many preliminary cullings is it best to make?

7. What special points should a breeding bird possess? 62 
Exercise 10 (Continued) 


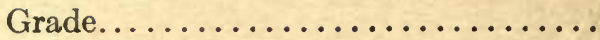

Date.

\section{EXERCISE 17}

\section{THE CARE OF THE LAYING PEN}

Object.-To become practically familiar with the details incidental to the feeding and daily care of the laying flock.

NotE.-If possible every student should be assigned one pen of birds for a given period, in order that he or she may practice personally the steps in this exercise. If individual practice work is impossible the entire class should be allowed at least one afternoon in which to see these chores performed in the proper manner by the instructor.

Equipment.-One or more completely equipped laying pens filled with birds, all necessary feed, tools and appliances required for daily chores.

Procedure.-Chore schedule for laying and breeding flocks. This must be slightly modified for winter and summer conditions.

Step 1.-7 a. m. daily:

(a) Feed morning grain ration, scattering it well in deep litter, about one pound to every twenty birds.

(b) Fill drinking vessels with clean, fresh water, being sure to rinse pans before refilling.

(c) Inspect dry mash hopper, being sure that mash is plentiful and feeding properly.

(d) Release birds from house, if they have been confined during the night. Step 2.-10 to 11 A. M. daily:

(a) Feed mangel beets or other succulence.

(b) Refill any water vessels which are nearly empty.

(c) Clean dropping boards and cover same with thin layer of gypsum (land plaster) or ground phosphate rock.

Step 3. -4 P. M. daily:

(a) Feed night grain ration, scattering same well in deep litter at the rate of one pound to ten birds.

(b) Add fresh water to any pans which seem to be low.

(c) Collect eggs and record in proper column on egg record. 64 


\section{EXERcise 17 (Continued)}

(d) Be sure perches are properly adjusted, hoppers feeding properly and everything in shape for the night.

Step 4. -6 to 8 P. M. daily:

(a) Visit all pens about dark, fastening them securely for the night.

(b) On cold nights in winter the water pans should be emptied.

(c) On very stormy, windy and cold nights the muslin curtains should be closed, at all other time they should be left open.

(d) Confine in broody coops any birds which are on the nests at this time. Why?

(e) Be sure birds are properly secured for the night.

Note.-Where trap-nests are operated, the visits can be made at the same time as the 7,10 , and 4 o'clock trips listed above with the addition of special visits at 11.30 A. M. and 1 P. M.

Leading Questions.-1. Why is attention to little details so important in attending to the poultry flock?

2. In what one way can this detail be accurately attended to?

3. What do you consider the most important factor in caring for the flock?

4. Why is the scattering of the grain in deep litter so important?

5. How can the water supply be kept clean and healthful?

6. When and only when should muslin curtains be lowered?

7. Why is it desirable to secure birds in the pen at night?

8. What factors can you use to determine whether one is feeding the proper amount of grain?

9. How often should the dropping boards be cleaned? 
EXERCISE 17 (Continued) 
Grade........................

Date........................

\section{EXERCISE 18}

\section{SANITATION IN THE POULTRY HOUSE}

Object.-To study an efficient method of cleaning and disinfecting the poultry house.

NoTE.-This work is best done in the morning in order that the house can become dry by night. It should only be done on a clear day.

Equipment.-One or more laying houses in which adult laying birds have been kept for a number of months; a complete barrel spray outfit and the following ingredients for the spray mixture: 5 quarts of freshly burned rock lime, 1 quart zenoleum or other equally good disinfectant, 1 quart kerosene. Have all necessary brooms, forks, shovels, hoes, etc.

Procedure.-Proceed in the work of sanitation as follows:

Step 1. - Shut the birds out of the house.

Step 2.-Remove all old litter and nesting material and spread on land for fertilizer.

Step 3.-Remove all portable fixtures, placing them out of doors.

Step 4.- Sweep the interior of the house thoroughly, especially walls, rafters and muslin curtains.

Step 5.-Spray the interior of the house with the following disinfecting solution: Take five quarts of rock lime and slake to the consistency of cream by the addition of boiling water. To this, after cooling, add one pint of disinfectant, agitating the mixture while thoroughly mixing. Dilute by adding ten quarts of water and then add one quart of kerosene, stirring violently. Before placing the mixture in barrel it should be well stirred and strained. Be sure to spray every part of the house, covering curtains and windows with burlap to keep them clean and dry.

Step 6.-Dry clean with broom and then spray all fixtures.

Step 7.-Return all fixtures to their proper positions.

Step 8.-Wash windows inside and out.

Step 9.-Place about ten inches of new clean litter over the floor and put new nesting material in nests. 


\section{Exercise 18 (Continued)}

Time Record.

\begin{tabular}{|c|c|c|c|c|c|c|c|c|c|c|c|c|c|}
\hline \multirow{2}{*}{ House No. } & \multirow{2}{*}{ Sise } & \multirow{2}{*}{$\begin{array}{l}\text { Number } \\
\text { of Birds }\end{array}$} & \multicolumn{10}{|c|}{ Time Required for Each Step } & \multirow{2}{*}{ Total } \\
\hline & & & 1 & 2 & 3 & 4 & 5 & 6 & 7 & 8 & 8 & 10 & \\
\hline & & & & & & & & & & & & & \\
\hline & & & & & & & & & & & & & \\
\hline & & & & & & & & & & & & & \\
\hline & & & & & & & & & & & & & \\
\hline 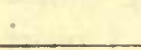 & & & & & & & & & & & & & \\
\hline Total & & & & & & & & & & & & & \\
\hline AVERAGE & & & & & & & & & & & & & \\
\hline
\end{tabular}

Step 10.-Allow the birds to enter the house and make sure that everything is in readiness for them.

Note.-This general cleaning should be done at least once each spring and fall and oftener if necessary.

Leading Questions.-1. Why is this general cleaning so important?

2. Why is the lime slaked with boiling water?

3. Why is the kerosene used?

4. What make of disinfectant was used and how much?

5. How long did it take to clean and disinfect the house?

6. What was the size of the house and cost per 100 square feet of floor space in material and time?

7. What three definite objects were accomplished by the use of the above solution?

8. Under what conditions would you make a general cleaning oftener than twice a year? 
Exercise 18 (Continued) 


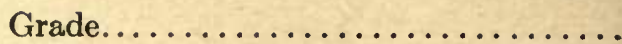

Date.

EXERCISE 19

\section{ANATOMICAL STUDY OF THE FOWL}

Object.-To study the anatomy of the domestic fowl and to become familiar with the location and appearance of the normal organs.

Equipment.-A number of live fowls, both male and female, and dissecting instruments.

Procedure.-Kill and dissect the birds in the following manner:

Step 1.-Kill the bird by dislocating the neck, or, better, by chloroform under bell jar.

Step 2.-Prepare the bird for post-mortem study by laying it on its back and fastening it securely to an operating table with wings and legs. Next cut the skin on the breast line, peeling it back each side as far as possible. Cut ribs and raise breast bone, bending it back so that organs are exposed, lying in their natural position.

Step 3.- Study the following organs and parts as to color, size, weight, shape and location, also their relation to other organs, function and general normal appearance: Liver, spleen, gall bladder, heart, crop, lungs, trachea, œsophagus, proventriculus, gizzard, pancreas, intestines, cæca, kidneys, ovaries and oviduct in females and testes in males.

Step 4.-Group the organs into the following systems and note the sequence and function of each organ to the system which it helps to make up: Digestive, Respiratory, Reproductive, Circulatory.

Step 5.-Dissect leg and breast muscles and trace relation of these muscles to control of flight in wings and movement of toes.

Step 6.-Dissect spinal column, including nerves and brain. Trace some of larger nerves such as optic nerve.

Leading Questions.-1. For this exercise, why should the birds be killed without bleeding?

2. What organs are exposed when the breast bone is bent back?

3. Describe the normal appearance of lung tissue, of liver tissue, and of spleen. 


\section{Exercise 19 (Continued)}

Classification of Organs

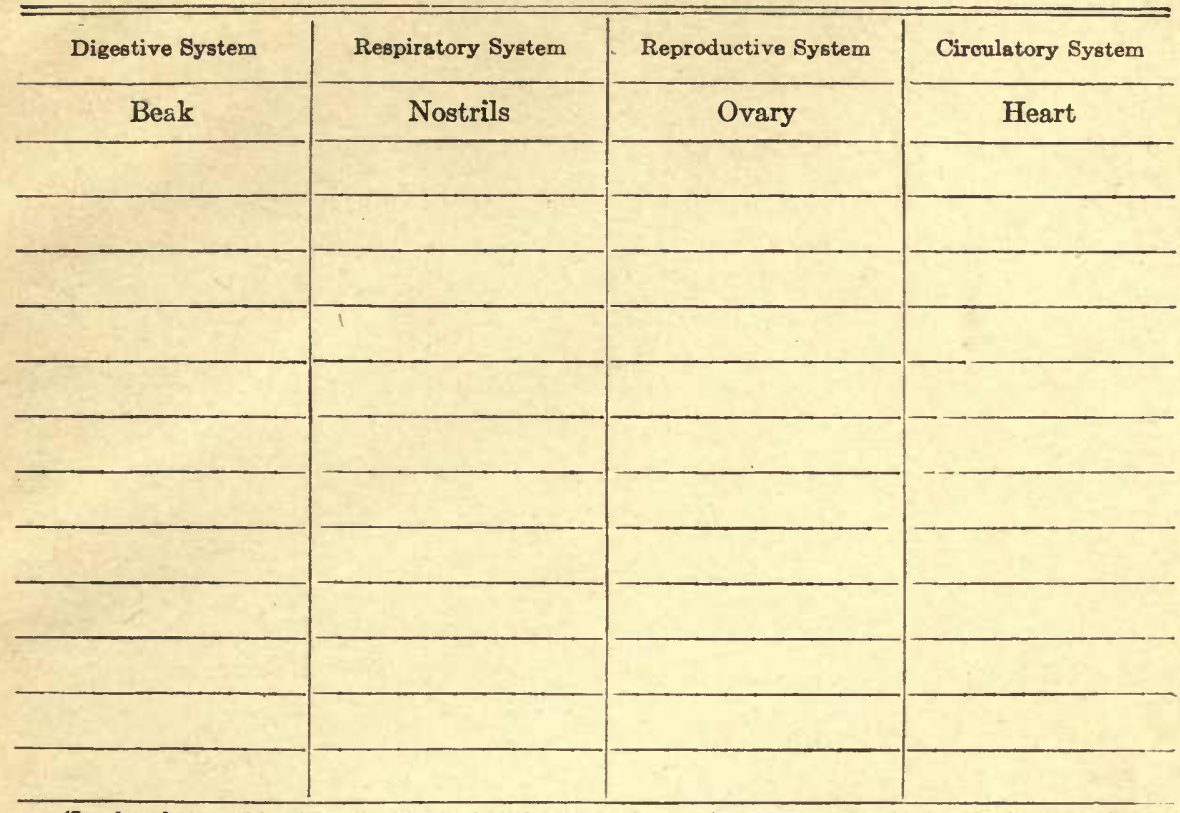

(In the above table classify organs of each system in proper sequence, beginning as designated.)

4. Name the organs of digestion in the order in which the food passes through them.

5. What was the length of the alimentary canal?

6. Describe the structure of the gizzard?

7. What is the function of the crop?

8. What was the weight of the intestinal organs in percentage of the total weight of the dead bird?

9. Describe the appearance of an active ovary and oviduct as contrasted to one which is inactive. 


\section{Exercise 19 (Continued)}


Exercise 19 (Continued) 
Grade........................

Date.

\section{EXERCISE 20}

\section{THE REPRODUCTIVE SYSTEM OF THE HEN}

Object.-To dissect and study in detail the reproductive system of the hen and to become familiar with the process of egg formation.

Equipment.-A number of hens (1) one or more in laying condition, (2) one immature pullet, and (3) one old hen, very fat.

Procedure.-Study these three different types of specimens as follows:

Step 1.-Open the birds for post-mortem inspection as directed in Exercise 19. Remove organs of digestion and circulation carefully, exposing the reproductive system.

Step 2.- Study in detail the location, size and appearance of the ovaries and oviduct in each specimen. Take complete notes regarding them. Where possible a number of birds should be studied in respect to ovarian development.

Ovaries and Ovules

\begin{tabular}{l|l|l|l}
\hline Hen No. & Condition of Ovary & Number of Large Ovules* & Number of Small Ovules \\
\hline & & & \\
\hline & & & \\
\hline & & & \\
\hline & & & \\
\hline & & & \\
\hline Totals & & & \\
\hline
\end{tabular}

* A large ovule should be at least one-quarter of an inch in diameter.

Step 3.-Carefully dissect the ovary and count the number of ovules (a hand lens will be a help in counting the small ones). Note the variation in size and color.

Step 4.-Carefully dissect the oviduct and remove to the dissecting tray. Note external appearance of the different sections. 74 


\section{Exercise 20 (Continued)}

Step 5.-Open the oviduct lengthwise and study the internal structure of the various sections. Note especially the funnel shaped end or infundibulum, the isthmus where the shell membranes are added and the uterus where the shell is added.

Leading Questions.-1. How many ovules are there in the average hen's ovary?

2. Describe the difference in appearance of ovules in a mature and immature hen.

3. Describe the difference in appearance of an oviduct in mature and immature hens.

4. What peculiar appearance did you find on the inside wall of the shellsecreting section of the oviduct?

5. What was the length of the oviduct in a hen when in laying condition? When in a non-laying condition?

6. What correlation is there, if any, to the number of ovules and the rapidity and number of eggs laid by a hen?

7. How do the yolks or ovules enter the oviduct?

8. In what part of the oviduct does fertilization take place?

9. How many times does the oviduct bend on itself?

10. Name the successive steps in the formation of a complete egg. 
Exercise 20 (Continued) 
Exercise 20 (Continued) 


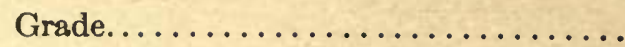

Date.

\section{EXERCISE 21}

\section{THE DEVELOPMENT OF A CHICK EMBRYO}

Object.-To dissect and study in detail the development of the chick embryo and to become familiar with the various stages in its development and the relation of same to the period of incubation.

Equipment.-A number of eggs containing.embryos of the following ages: 36 hours, 72 hours, 7 days, 14 days, and 19 days old; petri dishes, dissecting dishes, needles, and knives; drawing pencil, and a hand lens.

Procedure.-Proceed to study each of the five stages in the development of the embryo in their proper order in the following manner:

Step 1.-Break the shell very carefully and empty the contents of the egg to be studied into a larger petri dish without rupturing yolk or membrane. If the egg is opened under water there is less danger of rupturing the contents.

Step 2.-Look for the following organs and structures as they may appear in each successive stage:

Area palucida

Inner and outer amnion

Lobes of the head

Brain

Spinal cord

Heart
Pro-vertebrata

Wings

Legs

Beak

Eyes

Feathers

\section{Arteries and veins}

Step 3.-Make a drawing of each stage of embryo development stuäied, name and locate the organs and structures found. In the following table, list under each age the organs seen at that period. List new organs appearing at any period in red.

Step 4.-Open an egg containing a 72-hour-old embryo, emptying it into warm water. Observe the heart-beats. Count the rapidity of same and the length of time they continue.

Step 5.-Repeat the previous step, emptying the embryo into cold water, and observe the results.

Step 6.-Examine a number of embryos on the nineteenth day. Note their position in the shell and take full notes on their position.

Leading Questions.- 1 . How and where is the yolk sack attached to the embryo? 


\section{Exercise 21 (Continued)}

Embryo Development

\begin{tabular}{l|l|l|l|l}
\hline 36 Hours & 72 Hours & 7 Days & 14 Days & 19 Days \\
\hline & & & & \\
\hline & & & & \\
\hline & & & & \\
\hline & & & & \\
\hline & & & & \\
\hline & & & & \\
\hline & & & & \\
\hline & & & & \\
\hline & & & & \\
\hline
\end{tabular}

2. In succeeding stages of development what changes seem to take place in the amount and character of albumin and yolk material.

3. What organs are formed first? Why?

4. When do the wings and legs first appear?

5. When do the feather sacks first make their appearance?

6. What is the effect of heat and cold upon the heart-beat of the embryo and hence upon its development?

7. Describe the correct position of the embryo at hatching time.

8. Describe the process of hatching.

9. How does an embryo, dead on the seventh day, appear before the candle and upon dissection.

10. What do you believe to be some of the possible biological causes of death of the embryo during the last few days of incubation? 
Exercise 21 (Continued) 
Grade.......................

Date. .

\section{EXERCISE 22}

\section{THE SELECTION AND CARE OF HENS FOR HATCHING}

Object.-To become familiar with the best practice to follow in selecting desirable hens for hatching, kind and location of shelters, and the detily care of such hens.

Equipment.-Special types of shelters suitable for incubating hens such as barrels, boxes, special coops, and if possible, access to a house specially designed for such hens; a supply of broody hens, preferably American varieties; a supply of cut straw, some loose bricks and a supply of fertile eggs.

Procedure.-Proceed according to the following steps to set a given number of hens. All hens can be set at one laboratory period and different members of the class can be delegated to take care of them for definite periods or until hatching time.

Step 1.- Locate the shelters in some high, dry, protected, warm spot; preferably on the south side of a building, fence or bank. The shelters should be roomy, neat and natural and should be provided with a slatted door for ventilation.

Step 2.-Form the nest, one in each shelter, by placing loose soil or sods. Hollow out the center and be sure to keep corners high. A brick in each corner keeps them high and prevents the eggs from rolling out. Cover this formed nest with cut straw or hay, firming same and hollowing it in center. Dust nest with lice powder. Brush the corners and cracks with crude petroleum before the hay is put in place.

Step 3.- Select suitable hens, being sure that they are perfect in health. They should neither be thin nor too fat and should be of a quiet, gentle disposition, easily handled. Be sure that they are well possessed of the broody tendency. The breast should feel warm and be free from feathers.

Step 4.-Place each hen on her nest, after treating her with mercuric ointment. Confine hen a day on false eggs until she is tested and has proven her suitability for the purpose, after which good eggs may be placed under her in place of the false eggs.

Step 5.-Care for the setters each day as follows: Open nests morning and night and allow hens to come off to feed if they wish. Fresh water and whole grains containing considerable corn should be available. Be sure hens. 


\section{Exercise 22 (Continued)}

go back on the nests after about 30 to 60 minutes, depending on the weather. Treat birds with mercuric ointment on about fourteenth day of incubation.

Step 6.-Test eggs on the seventh and fourteenth days and keep a record for each nest showing the following facts:

1. Date when set................

2. Variety and kind of eggs.

3. Number of eggs

4. Seventh day, No. infertile eggs. .No. dead embryos.......

5. Fourteenth day, No. dead embryos..........

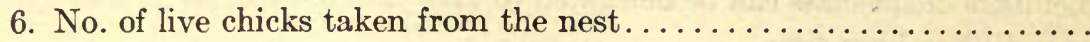

Step 7.-When the hatch is over, clean the nest and put the place in shape to house the hen and chicks for a few weeks or until the youngsters are large enough to shift for themselves on range.

Leading Questions.-1. Where do you consider the best place to locate hatching shelters?

2. What type of hatching coop do you prefer and why?

3. How large and how deep should a well-formed nest be made?

4. What is the best time of day to select and set hens?

5 . What points would you require in such hens?

6. Why do you darken the nest for the first few days of the incubation period?

7. How long does it take to care for ten hens and how many eggs can they incubate?

8. How many eggs could be cared for in incubators during this time?

9. Determine the proper routine for caring for setting hens?

10. How does natural incubation compare with the artificial method in efficiency? 
EXercise 22 (Continued) 
Grade........................

Date.

\section{EXERCISE 23}

\section{THE INCUBATOR-LOCATION, CONSTRUCTION, AND OPERATION}

Whenever possible each student should run one machine for an entire hatch in addition to performing this exercise.

Object.-To become familiar with the various types and sizes of incubators, to determine the principles of heat distribution and control and to become familiar with the details of operation.

Equipment.-As many representative types of incubators as it is possible to secure; include, if possible, mammoth and individual machines, of both hot air and hot water types.

Procedure.-Step 1.--Make a list of all machines to be studied, recording name, size, cost, and method of heat distribution (air or water).

Incubators Compared

\begin{tabular}{|c|c|c|c|c|c|c|}
\hline $\begin{array}{l}\text { Make of } \\
\text { Incubator }\end{array}$ & Capacity & Fuel Used & Cost & $\begin{array}{c}\text { Method of } \\
\text { Heat } \\
\text { Distribution }\end{array}$ & $\begin{array}{l}\text { Method of } \\
\text { Moisture } \\
\text { Supply }\end{array}$ & $\begin{array}{l}\text { Cost Per } \\
100 \text { Egg } \\
\text { Capacity }\end{array}$ \\
\hline & & & & . & & \\
\hline & & & & & & \\
\hline & & & & & & \\
\hline & & & & & & \\
\hline & & & & & & \\
\hline & & & & & & \\
\hline & & & & & & \\
\hline & & & & & & \\
\hline 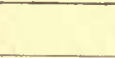 & & & & $x^{4}$ & & \\
\hline
\end{tabular}

Step 2.-Examine each machine, noting its external appearance, apparent durability, finish, material, and design.

Step 3.-Open the machine and examine interior construction, learning name and arrangement of parts.

Step 4.-Examine the source of heat, whether lamp or stove. Trace the 


\section{Exercise 23 (Continued)}

course of warm water or air, as the case may be, through the machine. Note any ventilators or air filters. Note character of bottom solid, or slatted.

Step 5. - What is the method, if any, of supplying moisture in each make of machine?

Step 6.-Study carefully the self-regulating device, note parts and their names, and record simplicity and apparent efficiency.

Step 7.-Take a representative machine to pieces and study its internal construction, as thickness and number of walls, insulating material used, with location and amount of same. Note pipes for distributing heat. Replace parts carefully and put machine again in working order.

Step 8.-From your experience as well as from this study, state which machines you consider the most effective, and why.

Leading Questions.--1. What materials do you find most commonly used in incubator construction? Name other materials used.

2. What is the limit of size in kerosene-heated machines?

3. What is the effective capacity of a single tray?

4. What special protection is provided to avoid fire in lamp-heated machines?

5. How many ways are there for controlling temperature automatically on small lamp-heated machines? On mammoth machines?

6. What is the general course of heat through an incubator?

7. How is excessive circulation of air across the eggs controlled?

8. What different ways of saturating the air with moisture did you observe in the machines studied?

9. What do you understand regarding the relative efficiency of hot air and hot water machines?

10. What are some of the most frequent causes of failure of an incubator to operate properly? 
ExFrcise 23 (Continued) 


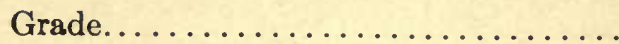

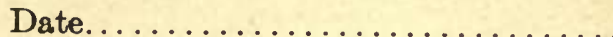

\section{EXERCISE 24}

\section{THE BROODER-LOCATION, CONSTRUCTION, AND OPERATION}

Object.-To become familiar with types and sizes of brooders, methods of locating and operating them, capacity, fuel, and temperature control.

When possible each student should run at least one machine for the first three weeks of a bronding period as supplemental to the work of this exercise.

Equipment.-Access to a complete brooding equipment, including long pipe brooders as well as small and large colony stoves and kerosene hovers. (This study may be extended by visiting near-by poultry farms and studying prevailing types of brooding equipment.)

Procedure.-Step 1.-Make a classified list of all brooders studied on the basis of the fuel supply-kerosene, coal, gasoline, and fuel oil.

Step 2.-Make another classification of colony stove brooders on the basis of capacity, fifty chicks, one hundred, three hundred, five hundred and one thousand chicks; also include cost of each in this classification.

Step 3.-Examine each stove brooder, noting its general plan of construction, such as external appearance, durability, simplicity, fuel supply, presence or absence of hover curtains. Classify stoves studied according to presence or absence of curtains.

Step 4.-Raise hover of a typical stove and study the details of construction, heat regulating device, damper control, location of thermostat, construction of grate, size of fire pot, and capacity of coal chamber.

Step 5.-Note the size of room or rooms in which the stoves are operated and what precautions are taken to keep chicks from crowding.

Step 6.-Classify mammoth pipe brooders on the method of distribution of heat to the hover area; as, overhead pipes or drum-heated circular hovers.

Step 7.- Note the construction of the long brooder house, the division into pens, the size and number of heated pipes and their arrangement for control of heat.

Step 8.-Study in detail the various types of kerosene-heated hovers, noting design, location of lamp, size of hover, capacity, portability, ease in attendance, and durability.

Step 9.-Make a record of all machines studied according to the following form: 


\section{EXERCISE 24 (Continued)}

Brooders Compared

\begin{tabular}{|c|c|c|c|c|c|}
\hline $\begin{array}{l}\text { Make of } \\
\text { Brooder }\end{array}$ & Type & Capacity & Cost & Fuel & $\begin{array}{r}\text { Cost Per } 100 \\
\text { Chick Capacity } \\
\end{array}$ \\
\hline & & & 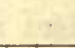 & $x^{2}$ & 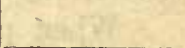 \\
\hline & & & $\sqrt{12}$ & $x^{2}$ & $\sqrt{2+25 x}$ \\
\hline & & & & & \\
\hline & & & $5+2$ & 12 & $x^{2}-2=0$ \\
\hline & & & 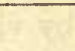 & 5 & $x+2 x$ \\
\hline & & & & & $x$ \\
\hline & & & s & 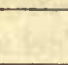 & \\
\hline & & & & $x$ & \\
\hline
\end{tabular}

Leading Questions.-1. What type of brooder do you find in most general use?

2. Which type offers the greatest capacity for the money invested?

3. Which type offers the greatest diversity of use and most economical investment?

4. What do you consider the most efficient capacity for coal-stove brooders?

5. What type and size of building is best adapted for the operation of a coal-stove brooder?

6. What advantages and disadvantages can be stated regarding the use of a hover curtain with coal stoves?

7. Is water or steam used in long-pipe brooder houses, and why?

8. Name two great disadvantages of kerosene hovers.

9. Enumerate advantages of a colony brooding equipment over a fixed, long-pipe, mammoth brooding equipment.

10. What are the possibilities of combining the colony stove and the mammoth pipe system?

11. Which brooder of all studied do you prefer and why? 


\section{Exercise 24 (Continued)}

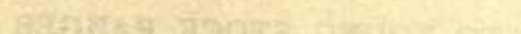

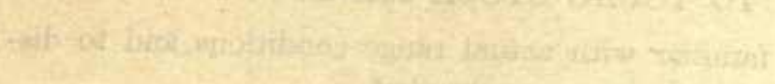

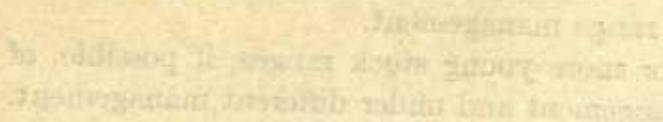

73:

Whationity

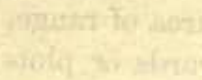

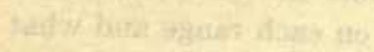

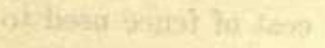

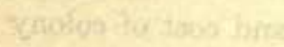




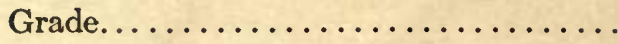

Date.

\section{EXERCISE 25}

\section{A VISIT TO YOUNG STOCK RANGES}

Object.-To become familiar with actual range conditions and to discriminate between good and bad range management.

Equipment.-Access to one or more young stock ranges, if possible, of varying sizes and of different arrangement and under different management.

Procedure.-Step 1.-Determine the area of range.

Step 2.-Determine into how many yards or plots the yard is divided.

Step 3.-Determine how many birds are reared on each range and what breed is kept.

Step 4.- Make an inventory of amount, kind, and cost of fence used to inclose each range studied.

Step 5.-Make an inventory of number, size, design, and cost of colony houses on each range studied.

Step 6.-Determine the cost of establishing a suitable range for one thousand birds.

Leading Questions.-1. What range area should be allowed for each one hundred chicks reared?

2. What sizes of flocks are reared together?

3. Is natural shade an asset? If so, what kind would you consider most desirable?

4. What crops are grown to provide green food?

5. What arrangements are made for watering the flock? Are these efficient?

6. What arrangement is made for feeding dry mash?

7. Are the colony houses elevated; if so, why?

8. How many square feet of floor space is allowed for each one hundred birds to be reared?

9. How many linear feet of perch is allowed for each one hundred birds?

10. Are light and heavy breeds grown together on the same range? What is the objection to this practice?

11. Are birds of different ages grown together? What is the objection to this practice?

12. What materials are used for litter in colony houses? feeding?

13. How are the ranges rotated with reference to crop production and 
Exercise 25 (Continued) 
Grade.......................

Date.

EXERCISE 26

\section{MARKET TYPES OF LIVE POULTRY}

Object.-To become familiar with classes and grades of market poultry, both live and dressed.

Equipment.-Live and dressed specimens of the following grades and classes of poultry: Broilers-small, medium, large; roasters-large and small; capons; fowls. Hanging scales weighing in tenths of a pound should also be available.

Procedure.-A. Study the live specimens as follows:

Step 1.- Separate them into their four classes of broilers, roasters, capons, and fowls, using separate cages for each class.

Step 2.-Determine and list the factors which you use in making this separation.

Step 3. - Study the broiler group in detail and separate them into their three grades, first by weighing the birds and later estimating the weights of each.

Step 4.-Repeat the same with the roaster group.

Step 5.-Compare capons and cockerels of the same age as to size, weight, plumpness, etc.

Step 6.-Handle and observe all classes and grades of birds carefully in order to become familiar with their appearance, weight and handling qualities.

Step 7.-Estimate the weights of representative specimens of each group and later make actual weights to determine accuracy of estimate and thereby develop the power of correct judgment.

$B$. Study the dressed specimens as follows:

Step 1.-Separate them into their four classes as broilers, roasters, capons, and fowls.

Step 2.-Separate each class into its component grades.

Step 3.-Handle and observe each class and grade to become familiar with their appearance, size, weight, and handling qualities. 


\section{Exercise 26 (Continued)}

Leading Questions.-1. What external differences are most noticeable between live broilers, roasters, and capons?

2. How can you distinguish between the three classes of broilers when alive?

3. How can you distinguish between large and small roasters when alive?

4. What are the external appearances of a staggy roaster?

5. How can the keel bone be used as an indicator of age?

6. In the dressed specimens, note the color of skin and plumpness of breast in all grades.

7. What are the limits of weights in all grades and classes studied?

8. How does the broiler demand vary with the season?

9. Which breeds make the best specimens in each class and grade?

10. What are the range of prices for each class and grade and what are their natural seasons of abundant supply? 
Exercise 26 (Continued) 


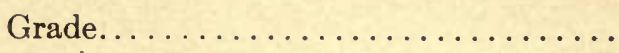

Date.

\section{EXERCISE 27}

\section{THE OPERATION OF CAPONIZING}

Object.-To study the details of and become expert in the operation of caponizing, and to determine the profits resulting from the practice.

Equipment.-One or more complete caponizing sets; caponizing table, in the absence of which a barrel will answer; a small quantity of disinfectant; a number of cockerels, about ten to fourteen weeks old, properly prepared for the operation by starvation for thirty-six hours or more. If the operation is to be performed out-of-doors a bright day is best; if indoors, an electric light on a hanging cord is of great advantage.

Procedure.-Step 1.-Weigh, band, and record age and variety of each bird before commencing to operate.

Step 2.-Perform the operation carefully, following detailed instructions given on pages 395 to 399 in Productive Poultry Husbandry, making close study of the illustrations.

Step 3.-Keep a record of all deaths and slips and the causes, and keep notes on all birds upon which you operate, stating apparent success of each operation.

Step 4.- Keep a record of the time required on each bird and observe increase of speed as you become more familiar with the operation.

Step 5.-Use different sets of instruments and determine the efficiency of each type.

Step 6.-Weigh the caponized birds at future intervals to determine rate of growth and, if possible, compare with a similiar lot of cockerels. From this data figure the financial gain from the practice.

Leading Questions.-1. What methods were used in preparing the birds for the operation?

2. What were the ages of the birds used? What age did you consider the best? 


\section{Exercise 27 (Continued)}

Caponizing Record

\begin{tabular}{l|c|c|c|c|c}
\hline \hline Band No. & Weight & Breed & Age & $\begin{array}{c}\text { Time Required } \\
\text { to Operate }\end{array}$ & $\begin{array}{c}\text { Sucess of } \\
\text { Operation }\end{array}$ \\
\hline & & & & \\
\hline & & & & \\
\hline & & & & \\
\hline & & & & \\
\hline & & & & & \\
\hline & & & & & \\
\hline & & & & & \\
\hline & & & & & \\
\hline
\end{tabular}

3. What was the average weight of the birds used in the exercise?

4. What breeds were used?

5. What breeds do you consider best adapted for capon production, and why?

6. In the total number of birds caponized, what was the per cent of slips, deaths, and successful operations?

7. Are these averages high or low in each case?

8. Which caponizing set did you like best, and why?

9. From the records kept, each operator should plot a curve showing the increase in his efficiency as indicated by increase in speed.

10. From your study and experience, what are the advantages to be gained from the practice of caponizing?

11. Under what practical commercial conditions would you grow a considerable number of capons? 
EXercise 27 (Continued)

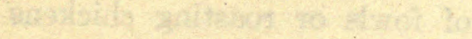

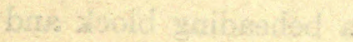

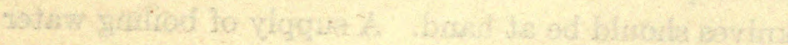

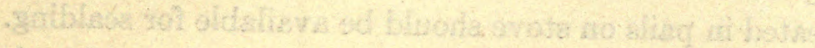

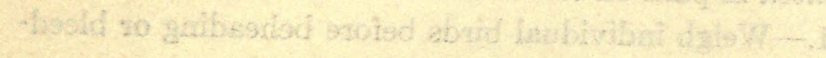

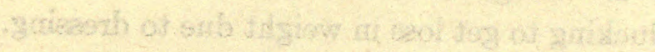

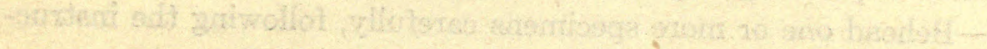

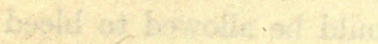

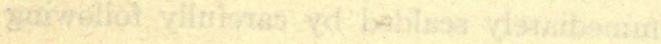

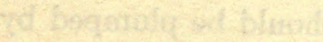

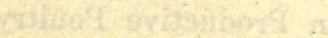

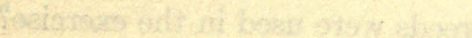

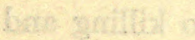

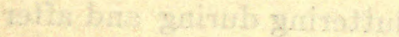

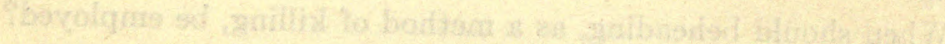

Saril

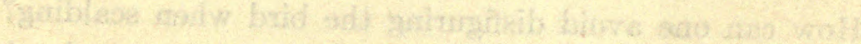

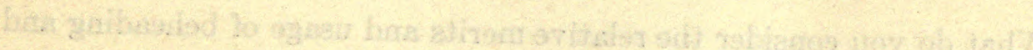

Stothatir

7 
'Grade........................

Date.........................

\section{EXERCISE 28}

\section{PREPARING DRESSED POULTRY FOR MARKET}

\section{Beheading, Bleeding, and Scalding}

Object.-To become familiar with the detailed technic incidental to the killing and plucking of poultry by the method of beheading and bleeding and the removal of the feathers by scalding.

Equipment.-Have a sufficient number of fowls or roasting chickens properly finished and prepared for slaughter, which includes being properly fattened and starved. A sharp cleaver or hatchet, a beheading block and different kinds of killing knives should be at hand. A supply of boiling water either in a caldron or heated in pails on stove should be available for scalding.

Procedure.-Step 1.-Weigh individual birds before beheading or bleeding, and again after plucking to get loss in weight due to dressing.

Step 2.-Behead one or more specimens carefully, following the instruction given on page 413 in "Productive Poultry Husbandry."

Step 3.-After killing an individual bird, it should be allowed to bleed thoroughly. It should then be immediately scalded by carefully following the instructions on page 414 in "Productive Poultry Husbandry."

Step 4.-Pick and clean the carcasses; then they should be plumped by immersion in cold water as described on page 417 in Productive Poultry Husbandry.

Leading Questions.-1. What breed or breeds were used in the exercise?

2. What was the average per cent of loss in weight due to killing and picking?

3. How was the bird handled to prevent fluttering during and after beheading?

4. When should beheading, as a method of killing, be employed?

5 . What was the temperature of the water when used for scalding?

6. How can one avoid disfiguring the bird when scalding?

7. How does scalding affect the keeping qualities and sale of birds so treated?

8. What do you consider the relative merits and usage of beheading and bleeding when killing poultry for market? 
Exercise 28 (Continued) 


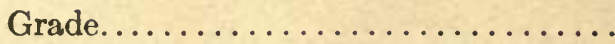

Date. .

EXERCISE 29

\section{PREPARING DRESSED POULTRY FOR MARKET}

\section{Bleeding, Sticking, and Dry Picking}

Object.-To become familiar with the details incidental to the killing and plucking of poultry by sticking and dry picking.

Equipment.-A sufficient number of broilers, roasters and fowls properly finished and prepared for slaughter, which includes being properly fattened and starved; one or more types of killing knives and suitable weights and cords for suspending birds; receptacles for blood and feathers conveniently arranged.

Procedure.-Step 1.-Weigh each bird before killing and again when plucked to determine the amount of shrinkage.

Step 2.- Suspend the bird to be killed as described on page 412 in Productive Poultry Husbandry.

Step 3.-Proceed with the killing, following instructions for bleeding and sticking as given on page 410 in Productive Poultry Husbandry. Be very careful to stick in proper form, or feathers will come out hard and tearing will be common.

Step 4.-Proceed with the plucking, following the instructions for plucking by the dry-picking method as given on page 413 in Productive Poultry Husbandry. Keep different grades of feathers properly separated.

Step 5.-Plump the carcass in cold water and wash head parts as described on page 417 in Productive Poultry Husbandry. Keep neat and accurate notes of all operations.

Leading Questions.-1. How were the birds prepared for slaughter?

2. What would have been the effect of leaving food in the crop?

3. How can you tell when you have made the proper cut in bleeding?

4. How can you tell when you have made the proper stick?

5. What are the important features in the proper suspension of the bird for sticking and picking?

6. What do you consider the best killing knife used?

7. When bleeding by sticking, how should the cut be made?

8. Which is the hardest to dry-pick, a broiler, a fowl, or a roaster? Why?

9. Which parts should be plucked first and why?

10. Where must greatest care in plucking be used, so as not to tear skin?

11. What is the average time which you require to dry-pick a broiler? A roaster? A fowl?

12. Why should the plucked carcass be cooled immediately, and how? 100 
Exercise 29 (Continued) 


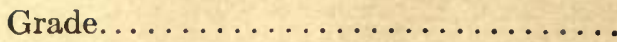

\section{EXERCISE 30}

\section{DRESSING AND TRUSSING MARKET POULTRY}

Objects.-To become familiar with the technic of dressing and trussing poultry preparatory to cooking; to become familiar with the method of carving poultry for fricassee.

Equipment.-A considerable number of properly plucked birds, including broilers, roasters and fowls; a suitable set of knives for dressing and carving.

Procedure.-Step 1.-Carefully prepare a small and large broiler for cooking; the former to be cooked whole and the latter to be cooked halved. Follow detailed instructions on page 418 in Productive Poultry Husbandry.

Step 2.- Prepare a roaster ready for the oven, following detailed instructions on page 418 in Productive Poultry Husbandry.

Step 3.-Prepare a fowl for fricassee. Take notes in detail on methods as demonstrated by the instructor.

Leading Questions.-1. Why are small broilers served whole and medium and large broilers halved?

2. What is the loss in weight in preparing a two pound broiler for cooking?

3. Why are all carcasses singed before cooking?

4. What is the loss of weight in preparing a roaster for cooking?

5. Into how many parts do you cut a fowl for fricassee?

6. What parts of the roaster and fowl are the most meaty?

7. What parts of the fowl's carcass are white meat and what parts dark meat? 


\section{Exercise 30 (Continued)}

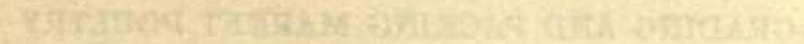

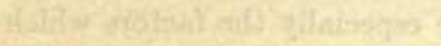

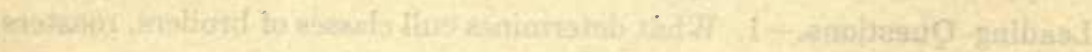

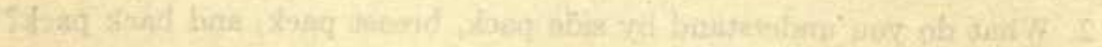

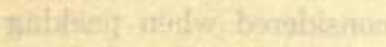


Grade...........................

\section{EXERCISE 31}

\section{GRADING AND PACKING MARKET POULTRY}

Object.-To become familiar with the proper manner of grading and packing dressed poultry for shipment to market.

Equipment.-A score card for dressed poultry; a grading table; boxes and barrels suitable for packing the finished product and plenty of finely chopped ice.

Procedure.-Step 1.-Grade a group of broilers into the following classes: (a) Sizes-squab, medium and large; (b) grades-prime, fair, poor, cull.

Step 2.-Grade a group of roasters into the following classes: (a) Sizeslarge and small; (b) grades-prime, fair, poor, cull.

Step 3.-Grade a group of fowls into the four classes according to quality as Prime, Fair, Poor and Culls.

NoтE.-In exercises four, five and six, note especially the factors which place the birds in their respective classes as to quality.

Step 4.-Determine from trade sheets and price reports the relative values of the different grades.

Step 5.-Judge classes of roasters by the score card method, using the score card found on page 492 in Productive Poultry Husbandry.

Step 6.-Pack a number of packages of broilers and roasters for shipment according to instructions on the bottom of page 444 in Productive Poultry Husbandry, being sure to use plenty of ice.

Leading Questions.-1. What determines cull classes of broilers, roasters and fowls?

2. What do you understand by side pack, breast pack, and back pack?

3. What are three special precautions to be considered when packing dressed poultry for shipment?

4. What is meant by wet and dry pack and when should each be used? 
Exercise 31 (Continued) 
Grade......................

Date.

\section{EXERCISE 32}

\section{CANDLING AND GRADING MARKET EGGS}

Objects. - To become familiar with the problem and technique of candling market eggs; to determine quality, and to become familiar with the grades into which market eggs are divided, when color, size and quality are all considered.

Equipment.-An adequate-sized room, darkened and equipped with at least two candling lamps; two cases of eggs, each mixed in color of shell, but new-laid; two cases of eggs purchased direct from the wholesale trade or country store which have never have been candled; a few eggs showing germ development, mould, and rot.

Procedure.-Step 1.-Study before the candle the appearance of a strictly fresh, new-laid egg; compare it with held eggs, germ-development eggs, mouldy eggs, and rots. Also note the appearance of cracked eggs and soiled eggs before the candle.

Step 2.-Each student should candle at least one case of eggs of general run and keep a record of the following:

a. Weight of case filled with eggs.

b. Weight of empty case after eggs are candled.

c. Weight of thirty dozen eggs and average weight per dozen.

d. Number and per cent of eggs candled out for the following defects: cracks or checks, leaks, spots, small, held, the latter being determined by the size of air cell. Observe any rots or mouldy eggs and any thin or malformed shells.

Step 3.-Knowing the original price of the crate before grading, re-value the eggs after grading according to grade. Determine the total value after grading, and the gain or loss.

Step 4.- Keep a record of the time it takes to candle one crate of eggs and determine the labor cost per crate at the rate of fifty cents per hour.

Step 5.-Ship to nearby large markets one crate each of white and brown eggs and one crate of mixed eggs, all of the same grade, as to freshness 106 


\section{Exercise 32 (Continued)}

and size. Compare the returns received, noting any discrimination due to color.

Leading Questions.-1. What are the requisites of a good candling lamp?

2. How many eggs can you candle in an hour?

3. How can the crates of eggs and receptacles be best arranged to facilitate the work?

4. What should a case filled with eggs weigh?

5. What should one dozen eggs weigh in each of the following classes: large, medium, small, culls?

6. What do you understand by the terms, checks, leakers, rots, spots, and dirties?

7. Taking the daily quotations on the day of this exercise, find the value of one crate of white eggs. How does this compare with the value of a case of brown eggs and a case of mixed colors? How do these compare with the actual prices returned for the last shipment made?

8. In packing a case of eggs for market, how can you largely prevent breaking?

9. When nailing on the top of a full case of eggs, what plan should you follow, to hold contents tight to prevent undue shaking and cracking?

10. How would you pack two hundred eggs to be shipped for hatching?

11. By what kind of transportation would you ship eggs to market? 


\section{Exercise 32 (Continued)}




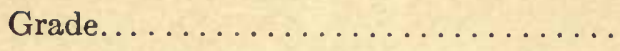

Date. . .

\section{EXERCISE 33}

\section{THE HOME PRESERVATION OF EGGS IN WATER GLASS}

Object.-To become familiar with the proper procedure incidental to the preservation of fresh eggs for home use, by water glass or the sodium silicate method; also to compare this method with any other preserving methods which may be available at the time.

Equipment.-At least one hundred strictly fresh, new-laid, infertile eggs; stone crocks holding from two to four gallons; clean water which has been boiled and cooled; sodium silicate liquid, about one quart, depending upon the number of eggs to be preserved; a candling device in order that the eggs may be candled before preserving; about six fertile eggs to compare with infertile eggs, after breaking, in order to detect the difference in appearance; a supply of eggs previously preserved.

Procedure.-Step 1.-Examine six infertile eggs after they have been carefully broken into a small glass dish. Study the white spot on the yolk. Use a hand lens, if possible. Make a similar study of six fertile eggs, and learn to detect the difference between the two types of eggs.

Step 2.- Lay down in water glass at least one hundred fresh eggs which have previously been candled and selected for cleanliness, for uniform size, and for good shells. Follow in detail the instructions given on pages 441 and 442 in Productive Poultry Husbandry.

Step 3.-Study the appearance of eggs which have been preserved for a considerable length of time and compare with a fresh egg. Observe the following: (a) Condition of the preserving liquid, including odor, color, density, and height in the jar.

(b). Appearance of eggs externally, whether slimy, coated, rough, or smooth.

(c). Candle test to determine size of air cell, and location of yolk, and density of contents.

(d). Carefully break a few eggs and note density, color, and odor of 


\section{Exercise 33 (Continued)}

albumin, also condition of the yolk as to density, color, and odor, and toughness of yolk sack.

(e). Cooking test. After hard boiling, observe taste, appearance and color.

(f). Whipping test. Separate yolks from albumin and see how readily the whites beat into froth.

Compare all of the above observations with fresh eggs treated in the same way. Keep accurate notes on the different observations and determine the efficiency of the preserving process.

Step 4.- Study as many methods of preserving eggs for home use as facilities will permit. Study especially the various methods of anointing the shells with oils and paraffin products.

Step 5.-Determine the cost of water-glass preservation, and find just how much is actually saved by the use of the method, by comparing prices of eggs at different seasons.

Leading Questions.-1. How can you tell a fertile from an infertile egg, when examining the yolk?

2. Why are infertile eggs better for home preservation?

3. Why is it necessary to sterilize the crock or jar and the water?

4. What per cent of water glass solution is best?

5. How many eggs will a pint of water glass preserve?

6. How large a crock or jar will be needed to preserve one hundred eggs?

7. What will be the cost of preserving thirty dozen eggs for home use in sodium silicate?

8. The resulting saving will amount to what in dollars and cents?

9. What seemed to be the general effect upon the eggs of the preserving process?

10. What one special precaution must be followed in using water-glass eggs? 
Exercise 33 (Continued) 
Grade.......................

\section{EXERCISE 34}

\section{SYSTEMATIC ADVERTISING}

Object.-To become familiar with the means of advertising; the principles of writing and displaying advertising; and to determine costs of advertising.

Equipment.-Drawing paper, foot rule, hard pencil, ruling pen, lettering pen, and brush.

If enough time can be spent on this work, a supply of water colors will enable the working up of very attractive display features.

Procedure.-Step 1.-Determine the different methods of advertising to be worked out, being sure to include a majority of those recommended in the text.

Step 2.-Determine a name for the farm to be advertised, selecting one which is especially appropriate to the location or product to be sold.

Step 3.-Design a trade-mark, which should be neat, simple, attractive, and suggestive.

Step 4.-Work out in detail an exact copy of all advertising features tc be included in a complete plan; such as, farm name on wagon, farm bulletin board, stencil for packages and shipping coops, letter heads, mating lists, and any other forms which it may seem wise to include.

Step 5.-After working details out in pencil and after their approval by the instructor, ink them with pen and brush, using colors where desirable.

Leading Questions.-1. Enumerate at least twelve different and distinct ways of advertising which might be included in a complete systematic advertising plan.

2. Why did you select the farm name which you used?

3. What led you to select the trade-mark used?

4. What are the uses of a farm bulletin board?

5. How can records of performance best be used in the advertising scheme?

6. What kinds of guarantee can be made for both stock and eggs, and what are the advantages of such from selling point? 


\section{Exercise 34 (Continued)}

7. What can you say of simplicity vs. elaborateness in developing an advertisement?

8. What do you consider the greatest possible weakness in advertising propaganda?

9. What must be the one underlying principle in writing all advertisements?

10. Enumerate at least ten poultry farms which have attracted your attention as having desirable farm and trade names and as being well advertised. (This last question can be best answered after a somewhat careful and complete study of Poultry Journal Advertising.) 
Exercise 34 (Continued)

114 
Exercise 34 (Continued) 
Grade.........................

Date..............................

\section{EXERCISE 35}

\section{PLANNING SIMPLE POULTRY RECORDS}

Object. - To become familiar with kinds of poultry records, methods of making and classifying them, and the importance of a well planned system of records.

Equipment.-Access to files of poultry research records, as well as acquaintance with and access to various forms of farm poultry records, blank paper and drafting equipment.

Procedure.-Step 1.-Study the files of records carefully to determine form in which records are kept and method of indexing and keying results.

Step 2.-Study the blank forms, noting which of the three most common methods of keeping records (loose leaf, card files, or sheet) are used.

Step 3.-Make a careful list of records which should be kept on a wellmanaged poultry plant of one thousand or more birds, such as incubator, brooder, feed, and egg records. State what form and size would be the most useful, and show how they should be keyed and filed for reference. Much study should be given the above list before it is finally adopted.

Step 4.-Proceed to make a copy of each record included in your list above, giving the exact size of forms, ruling, and printing.

Leading Questions.-1. What type of record did you find in most general use?

2. Which type do you personally consider the best and why?

3. What method of filing records appeals most to you?

4. What size of records do you consider most useful?

5. What do you consider the most important requirement of a complete set of record blanks?

6. What record forms do you consider the most essential for the proper management of a commercial poultry farm?

7. Is it possible to combine certain records and thus save time, labor and materials? If so, to what extent?

8. In planning records, what space should be left between lines where data must be written.

9. Is it a desirable plan to arrange for much copying of data?

10. What method can best be used to keep original pen, incubator and brooder records clean and neat?

11. Are records of any real, vital importance in poultry management? If so, in what way? 


\section{Exercise 35 (Continued)}


Grade....................

Date.

\section{EXERCISE 36}

\section{PLANNING SIMPLE POULTRY FARM ACCOUNTS}

Object.-To become familiar with methods and details of farm accounting and to work out a simple, yet efficient, system of accounts for a commercial poultry farm.

Equipment.-Have access to one or more actual sets of poultry farm accounts, covering at least one complete year. Copies of numerous standard farm accounting systems and books used in same should be available for study. Single entry, as well as double entry, books should be at hand in permanent and loose-leaf form.

Procedure.-Step 1.-Divide an average poultry farm into its essential departments, such as laying stock, breeding stock, incubation, brooding and young stock branches.

Step 2.- Show in outline form what books it would be desirable to keep and what accounts it would be necessary to open in a double-entry system of book-keeping, if the financial standing of each department, above listed, is kept distinct and accurate.

Step 3.-After becoming familiar with the plan and possibilities of the column-system of book-keeping, as described on page 465 in Productive Poultry Husbandry, make a sketch showing the proper headings and rulings for a combined day-book, cash-book, and ledger, covering all departments enumerated in the previous paragraph. Show simple entries for one month in such a way as to explain how the system will work.

Step 4.-Make a complete classified outline for a poultry farm inventory in such a way that the values assigned to each part may be simply filled in on the form.

Step 5.- Make a complete form on which to show a financial balance or yearly statement of profit or loss. 


\section{Exercise 36 (Continued)}

Leading Questions.-1. What departments of an average commercial poultry farm do you consider important enough to warrant separate financial statements?

2. What is the great advantage of such departmental study?

3. Why is a double-entry system not more generally used?

4. Define the column system of accounting and state its uses.

5. Name two important advantages possessed by the column system.

6. What is meant by a bill payable and a bill receivable? How could accounts of these be included in the column system?

7. Why is an inventory so essential in making a financial statement or balance?

8. When is the best time to make an inventory on a poultry farm? Why?

9. An inventory should be divided into certain very distinct and pronounced groups; what are these groups and why are they so important?

10. What is your conception of the two terms "debit". and "credit" as applied to the keeping of detailed expenditures and receipts? 
Exercise 36 (Continued) 
Exercise 36 (Continued) 
Exercise 36 (Continued) 


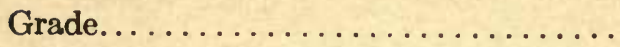

Date.

\section{EXERCISE 37}

\section{PREPARING POULTRY FOR EXHIBITION}

Object.-To become familiar, through actual practice, with the operation of washing and conditioning poultry for exhibition. (It is possible in one short laboratory period to cover the more important and practiced methods. A demonstration by a professional conditioner will be a wonderful help.)

Equipment.-Three galvanized wash tubs of good size, ivory soap, liquid bluing, a small scrub brush, vaseline, an electric or hand fan, a warm room for drying, and clean coops in which to dry the birds after washing.

Procedure.-Step 1.-Select a number of birds to be conditioned, mostly with white plumage and shanks free from feathers.

Step 2.-Go over each specimen critically to see that it is free from any disqualifications such as side sprig, wry tail, white in face, stubs, etc. If such a defect is present, the bird should not be shown. In the case of down between the toes or on the shank, it is the general practice to remove it, using care not to tear the skin or leave a wound.

Step 3.-Go over each specimen to be conditioned carefully and remove any solid or broken feathers or any of foreign color in all sections where missing feathers do not disqualify. Also clean the shanks and remove any old or badly discolored scales.

Step 4.-Wash and rinse each bird thoroughly, and follow exact procedure as discussed on page 479 in Productive Poultry Husbandry. Use special care to scrub shanks and feet, also comb and head parts. Be sure to work suds thoroughly through feathers and to rinse completely.

Step 5.-Dry each bird individually, allowing it to dry out considerably before placing it in the coop. The wing and tail feathers should be webbed out with aid of a fan before the bird is placed in a coop. The drying coop should be placed in a warm room, free from direct draft. Plenty of clean shavings should be placed on the floor of the drying coop. 


\section{EXercise 37 (Continued)}

Leading Questions.-1. Upon what points of merit is the first selection of exhibition specimens made?

2. Upon what points of defect is the first elimination made?

3. What are some of the more common disqualifications which it is possible to hide or remove by clever conditioning?

4. Why is ivory soap desirable for washing birds?

5. Why is warm water preferable to cold water for the washing?

6. Bluing is used for what purpose and in what amounts?

7. Why must considerable care be used to web out the flight and tail feathers immediately?

8. What is the proper drying temperature?

9. What would you expect would be the result of incomplete rinsing?

10. What would be the effect of repeated washings? 
Exercise 37 (Continued) 
Grade........................

Date........................

\section{EXERCISE 38}

\section{JUDGING STANDARD BRED POULTRY BY THE SCORE CARD}

Object.-To become familiar with the use of the score card, and to be able to determine the relative merits of a number of specimens by scoring. (The score card makes possible an understanding of the relative values applying to the different sections of a bird and is especially useful in learning the technic of judging.)

(More than one period should be devoted to this work, if possible. All of the more popular standard breeds should be studied and scored, including all classes of each, especially cockerel and pullet.)

Equipment.-A supply of score cards properly standardized for the breed to be scored; a battery of individual coops to hold the birds; five or more birds of the same variety, age, and sex; a copy of the Standard of Perfection of the most recent issue.

Procedure.-Step 1.-Study the score card carefully and determine the sections into which the bird is divided, studying at the same time the relative values given to each section.

Step 2.-Study the Standard of Perfection closely to become familiar with the standard requirements and descriptions of each section. Compare some representative specimens with the descriptions in order to make them more clearly understood.

Step 3.-Score a single specimen individually and later check your score with the correct score made by the instructor. Repeat this procedure with a considerable number of birds.

Leading Questions.-1. Into how many sections is a bird divided for scoring?

2. What are these sections?

3. Which sections are of the greatest numerical value and which the least? Why?

4. Name at least six common disqualifications which you have observed?

5. Define the term "cut" as it is used in scoring poultry.

6. How would you handle a bird when scoring it?

7. In what order would you score the various sections?

8. What must a bird score to be worthy of a prize?

9. How is the score of a pen computed?

10. What are the uses of the score card method of judging? 126 
Grade

Date.

\section{EXERCISE 39}

\section{JUDGING POULTRY BY COMPARISON}

Object.-To become familiar with a sure, quick and efficient method of determining the relative standing of two or more specimens of live poultry by comparison.

Equipment.-A battery of five or more individual cages to hold the class of birds to be judged; a considerable number (at least five) specimens of the same variety, age, and sex; a copy of the Standard of Perfection; small blank cards on which to note points of merit or defect as they may be observed.

Procedure.-Step 1.-Practice handling single specimens in the proper manner, taking them from and returning them to the cages many times until speed and experience is secured.

Step 2.- Inspect each individual specimen carefully for disqualifications, eliminating any showing such defects.

Step 3.-Inspect the class to be judged carefully for type. By comparing with the Standard of Perfection, place each specimen in order of excellence on a basis of type only.

Step 4. - Study the class carefully for surface or outer color, and after comparing the standard descriptions place specimens in order of excellence on a basis of surface color only.

Comparative Judging, Considering Type and Color

\begin{tabular}{|c|c|c|c|c|c|}
\hline \multirow[b]{2}{*}{ Band No. } & \multirow{2}{*}{ Disqualifications } & \multicolumn{3}{|c|}{ Standing with Regard to } & \multirow{2}{*}{ Final Placing } \\
\hline & & Type & Surface Color & Under Color & \\
\hline & & 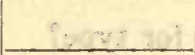 & brifuer a & Latales: & - \\
\hline & $\because .500+2$ & 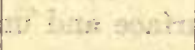 & $\because+b x, \ldots$ & 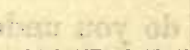 & $x+y=$ \\
\hline $40 \%$ & 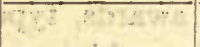 & 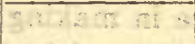 & 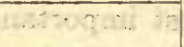 & 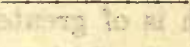 & 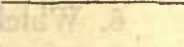 \\
\hline & & & $\sqrt{\frac{1}{4}}$ & 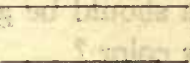 & 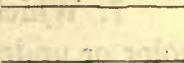 \\
\hline 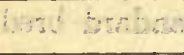 & os atwit & fituonace & 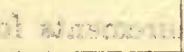 & pose $+111+50$ & $\because 78+8=0$ \\
\hline$\therefore$ & & & & & 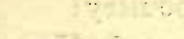 \\
\hline$\because 3040$ & 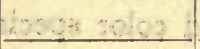 & 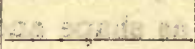 & Cunas + foco & $1+3{ }_{1}+0=0$ & $=010$ \\
\hline & & & & Fbothom $\mathrm{s}$ & 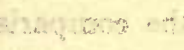 \\
\hline
\end{tabular}




\section{Exercise 39 (Continued)}

Step 5. Study class carefully for under color, and after comparing with standard description place specimens in order of excellence on basis of under color only.

Step 6.-Finally, place all specimens in order of excellence on the basis of combined qualities of type and color, being sure to bar from competition any specimens which have disqualifications.

Step 7.- In order to aid one in judging more accurately and in order to make a record of good and bad points some form of marking is usually employed. These marks are generally known only to the judge and are the results of his personal study. An excellent system is to let the letter $\mathrm{X}$ stand for type and the letter $\mathrm{C}$ stand for color. These marks or notations are made on the coop number tag in such a way that the specimens having the largest number of X's is best for type, and so on down to the poorest, which would probably show no $\mathrm{X}$ mark. The same plan would follow with the color designation, except that $\mathrm{C}$, when placed above a horizontal line, can represent surface color and $\mathrm{C}$ below the same line under color, as $\frac{c c}{c c c c}$. Abbreviations can be used to record disqualifications. Final awards would be made on a basis of the number of type and color marks showing on the cards, together with the considerations of the general health and vigor of the specimens.

Leading Questions.-1. How should birds be taken from judging cages for close inspection with the least injury to their condition?

2. What disqualifications do you find most common?

3. How many views of a bird should one get to properly determine type? What are they?

4. When should a class be judged for type?

5 . What do you understand by surface and under color?

6. Which is of greatest importance in making awards, type or color?

7. Which should be given the greatest weight in making awards, surface color or under color? poultry?

8. What are the requirements for a successful judge of standard bred

9. How is a pen judged by the comparison method?

10. How are special awards, such as shape and color specials, made by the comparison method? 
Exercise 39 (Continued) 
Grade........................

\section{EXERCISE 40}

\section{POULTRY DISEASE DIAGNOSIS}

Object. - To become familiar with the appearance of healthy and diseased birds and to become acquainted with the appearance of normal and diseased organs by post-mortem diagnosis.

Equipment.-Have ready at least one male and one female of healthy normal birds and a number of sick birds, which from ante-mortem appearance are probably afflicted with a number of diseases. These specimens can possibly be solicited for class use from poultry farms in the vicinity. At least one complete set of instruments for diagnostic work, a hand lens, and a suitable table, and dissection tray are needed. A porcelain receptacle containing a disinfectant solution is desirable. A compound microscope should be available if micro-biological and bacteriological observations are to be included.

Procedure.-Step 1.-Study a normal healthy specimen in detail, noting breed, sex, age, weight, condition of flesh, appearance of plumage, color of head parts, and general appearance of health and vigor. Study each sick or diseased specimen in detail, making all possible ante-mortem notes as to

Ante-mortem Study

\begin{tabular}{l|c|c|c|c|c|c|c|c}
\hline \hline Band No. & Breed & Age & Weight & Sex & $\begin{array}{c}\text { Appear- } \\
\text { ance of } \\
\text { Plumage }\end{array}$ & $\begin{array}{c}\text { Color } \\
\text { Head } \\
\text { Part }\end{array}$ & $\begin{array}{c}\text { Evidence } \\
\text { of } \\
\text { Disease }\end{array}$ & Diagnosis \\
\hline & & & & & & & & \\
\hline & & & & & & & & \\
\hline & & & & & & & & \\
\hline & & & & & & & & \\
\hline & & & & & & & & \\
\hline
\end{tabular}




\section{Exercise 40 (Continued)}

appearance and symptoms. From this study make an estimate of the possible affection, and note its probable cause and treatment, if any.

Step 2.-Kill each specimen observed, either by dislocating neck or by chloroform, the latter being preferable for careful diagnosis. Remove feathers from entire carcass where careful work is desired.

Step 3.-Open abdominal cavity for post-mortem examination by the following procedure: Cut skin on middle of breast and abdomen on line from cloaca to neck. Pull skin off sides of abdominal wall and dislocate thigh joints, spreading the legs and wings so the bird will lie flat on back with breast exposed. Fasten bird to operating table or pan, extending beak, wings and feet and fastening from these points. Cut flesh and bones at sides and bottom of sternum and remove the same completely by dislocating it at the clavicle and severing flight muscles. The abdomen and thoracic cavities are now exposed with all their organs in normal position.

Step 4.- Study each of the following organs in the order named and compare with those in a normal specimen, which specimen should have

Post-mortem Study

\begin{tabular}{l|c|c|c|c}
\hline Band No. & $\begin{array}{c}\text { List all } \\
\text { Normal Organs }\end{array}$ & $\begin{array}{c}\text { List all } \\
\text { Abnormal Organs }\end{array}$ & $\begin{array}{c}\text { Nature of the } \\
\text { Disease }\end{array}$ & Probable Cause \\
\hline & & & & \\
\hline & & & & \\
\hline & & & & \\
\hline & & & & \\
\hline
\end{tabular}




\section{EXERCISE 40 (Continued)}

previously been prepared for examination in the same manner. Observe carefully any evidences of abnormality or disease.

$\begin{array}{lll}\text { Peritoneum } & \text { Proventriculus } & \text { Testicles or ovaries } \\ \text { Crop } & \text { Gizzard } & \text { Oviduct } \\ \text { Esophagus } & \text { Intestines } & \text { Heart } \\ \text { Liver } & \text { Cæca } & \text { Lungs } \\ \text { Gall bladder } & \text { Pancreas } & \\ \text { Spleen } & \text { Kidneys } & \end{array}$

Step 5.-From diagnosis state probable disease and possible cause.

Step 6.--If time permits, the structure of each organ can be examined microscopically and the appearance of healthy tissue determined. Possibly, bacterial growth can also be isolated and studied.

Leading Questions.-1. Name evidences of health and vigor in a normal bird.

2. Name possible evidences of sickness in a live bird.

3. What are the relative advantages of an ante-mortem and a postmortem diagnosis?

4. Why is chloroforming a better way of killing a bird for post-mortem work then by breaking the spinal column near its junction with the head?

5. Describe the normal appearance of the following organs: Liver, cæca, lungs, ovary, gall bladder.

6. What are the most common causes of death in poultry?

7. Classify the common diseases on the basis of the organs attacked.

8. Classify poultry diseases on the basis of their mode of infection.

9. What do you consider to be the relation, if any, between chicken pox, roup, and canker?

10. To what extent are ovarian disorders in hens responsible for deaths? 
Exercise 40 (Continued) 


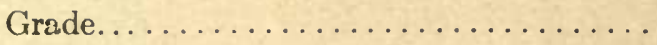

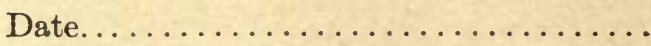

\section{EXERCISE 41}

\section{HOME PREPARATIONS AND STUDY OF POULTRY MEDICINES}

Object.-To become familiar with simple, home-made remedies and their best use.

Equipment.-Scales weighing in ounces, and fractions thereof; 16-ounce graduate; mortar and pestle; large-neck glass bottle for mixing medicines.

Procedure.-The following poultry medicines should be in the possession of every poultry man and kept in a cabinet. Study each in appearance, learn its use and proper dosage.

Calomel
Castor oil
Catechu
Cayenne pepper
Epsom salts Bichloride of mercury Salicylic acid Bismuth nitrate
Aconite root

Carbolated vasoline Iron, quinine and strychnine tablets

Step 2.-Mix the following tonic or conditioning powder. The formula is: $1 \mathrm{lb}$. pulverized gentian, $1 / 2 \mathrm{lb}$. pulverized iron sulphate, $1 / 4 \mathrm{lb}$. pulverized saltpeter, $1 / 4 \mathrm{lb}$. pulverized ginger. Mix and use two to three tablespoons of this in ten quarts of mash.

Step 3.-Mix the following ointment to be used for body lice: 1 part blue ointment, 1 part vaseline. Rub well into down and skin adjacent to vent, making two applications with ten days intervening.

Step 4.-Mix the following lice powder. This is known as Lawry's lice powder and the formula is: 1 part crude carbolic acid, 3 parts gasoline. Approximate five parts by volume of plaster of Paris. Spread out to dry for twenty-four hours, after which keep in air-tight container. Apply by dusting well into body plumage.

Step 5. - Study the poultry press for advertisements relating to standard medicines and disinfectants.

Leading Questions.-1. Classify poultry medicincs according to their medicinal properties.

2. Give the use and doses for the tonic just mixed.

3 . Give the use and doses for the lice ointment just mixed.

4. Why was gasoline used in mixing the above lice powder?

5. Name at least six commercial lice powders.

6. Make a list of twenty advertised poultry medicines.

7. Which do you prefer, ointment or powder for body lice?

8. Compare these with crude petroleum for this purpose.

9. Name at least six satisfactory commercial disinfectants.

10. To what extent should the poultry stock be doctored? 
Exercise 41 (Continued) 
Grade........................

Date..............................

\section{EXERCISE 42}

\section{TRIP TO A SUCCESSFUL POULTRY FARM}

Object.-To become familiar with plan and layout of plants; with size, style and construction of buildings, and to learn everything possible about methods of management and possible expenses and revenue.

Plan. - The trip should be made by a party of students accompanied by an instructor. The itinerary should have been previously arranged and the visit should be anticipated by the proprietor of the farm or farms to be visited.

Procedure.-Step 1.-Upon arrival at the farm, the visiting students should meet the proprietor and an opportunity should be given immediately for him to tell the students important facts about his farm. With these facts in mind it will make the inspection trip much more interesting and valuable. At the conclusion of the visit another opportunity should be given for the students to question the proprietor relative to points not previously covered.

Step 2.-During the visit the following facts, or as many of them as possible, should be determined by each student. Direct questions and observations will both serve to secure the facts.

Step 3.- Score the plant in detail according to the score card found on page 493 in Productive Poultry Husbandry. (These forms, for steps 2 and 3, can well be printed on cards to make the scoring easier.)

Step 4.- - After the visit has been concluded, probably at a later day, the class should make up a financial statement of the farms studied, in order to determine financial possibilities of the business.

Step 5.- - If time permits, each student should write a short essay, describing the different farms visited and telling which pleased him best, and why.

Leading Questions.-1. What general criticism would you make of the place visited?

2. What general commendation would you make of the place visited?

3. Was the farm appropriately named?

4. Was sufficient yard room allowed both young and old stock?

5. Were proper sanitary measures employed?

6 . What was the total inventory value of the farm?

7. What do you estimate to be the probable total expense of operating this farm?

8. What would you estimate to be the probable revenue from this farm, and from what sources?

9. What profit would you expect from this business each year?

10. How could this plant be made more profitable? 


\section{EXercise 42 (Continued)}

Name of farm.

Name of owner.

Location

Size of farm

and shape of same

Type of soil

Contour of land.

Crops grown and acreage of each

Area devoted to adult stock.

Area devoted to growing stock

Number, style, capacity and cost of buildings

Number of birds wintered and the breed

Number of birds incubated and the per cent of hatch

Number of chicks brooded and the per cent of brood

Rations used

Cost of feeding a bird per year.

Yearly egg production.

Value of plant, equipment and stock

Sources of revenue

Approximate amount of revenue yearly

Labor employed......... Number and wages paid.

Amount of advertising done

Health of flock and sanitary condition

General efficiency of plant and the methods of management.

A statement from the owner as to the possibilities of the business 
Exercise 42 (Continued) 


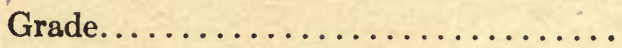

Date..........................

\section{EXERCISE $43^{\circ}$}

\section{TRIP TO WHOLESALE AND RETAIL POULTRY AND EGG MARKET}

Object.-To study and become familiar with methods and organization incidental to the distribution of poultry products, including commission business, retail business, city markets and cold storage.

Equipment.-Note book, camera, competent guide, and carefully planned itinerary.

Procedure.-The markets visited and the nature of the itinerary will be determined largely by local conditions. It is impossible here to give any itinerary which will suit all locations. The plan will be to give a suggested itinerary for New York City, which can simply be used as a guide in making up such trips for other cities and can be used by those wishing to visit that section.

Whenever itinerary is made up, all places which it is expected to visit should be notified in advance and their consent secured before the date of the visit.

\section{Step 1.-Suggested itinerary:}

7.15 A. м. Washington Market, Fulton and Vesey St., West Washington Market.

9.00 A. M. John Corell, 334 Washington St.

10.00 A. M. New York Mercantile Exchange, Hudson and Harrison Sts.

10.45 A. M. Merchants Refrigerator Co., 35 North Moore St.

12.00 to 1.00 Lunch

1.00 P. м. Collins and Barnard, 336 E. Washington St.

1.30 P. м. B. Titman and Co., Egg Breaking, 94 Moore St.

2.00 P. M. Fox River Butter Co., 78 Hudson St.

2.30 P. м. S. S. Long and Co., 102 Warren St.

3.00 р. м. W. S. Douglass and Co., 137 Reade St.

Step 2.-Instructions to class: Time of meeting and train to be taken, including tickets necessary to purchase. Party to remain together at all times. If, for any reason, members of the party become separated they should consult schedule and meet the party at the next place. Ask any appropriate questions, observe carefully, and make one's self agreeable to the market man. Take notes in as full detail as possible. 


\section{EXercise 43 (Continued)}

Leading Questions.-1. Make a record of the names and addresses of wholesale egg dealers as seen while passing on the streets.

2. Note the general location of the wholesale houses with reference to place in city and consolidation. What is the reason for such consolidation?

3. Why are these business houses located as they are?

4. What is the relative size of the establishments visited as measured by the volume of business?

5. How do the houses visited compare with reference to sanitary conditions and cleanliness?

6. Observe carefully how the candler works, especially as to the arrangement of the eggs and different grades he makes.

7. Describe the practice and use of egg breaking.

8. What are the methods which prevail in the cold storage of eggs?

9. What are your impressions of Washington Market as a place where the customer can purchase economically?

10. What are the two most important things which you have learned from this trip? 


\section{EXERCise 43 (Continued)}


Grade.......................

Date.

\section{EXERCISE 44}

\section{TRIP TO A STANDARD-BRED POULTRY SHOW}

Object.-To become familiar with breeds of poultry, with methods of staging, judging and managing a show; also to become acquainted with the breeders of the more popular varieties of poultry. The study of poultry appliances, feeds and educational exhibits is made possible to a wonderful degree by a trip of this nature.

Procedure.-The trip should be made by a party of students accompanied by an instructor. Upon arrival at the show a catalogue should be procured, and the show should be divided into certain well-defined groups and studied as follows:

Step. 1. Study the exhibits of poultry, including these points:

(a) Number of specimens and quality in each class. (b) Breeders of winning specimens. (c) Study the advertising and cage displays. (d) Note, and if possible meet, the judges placing the awards.

Step 2.-Study the exhibits of water fowls, turkeys and pigeons, learning the identity and appearance of the various varieties.

Step 3.-Study the various poultry appliances on exhibition, collect advertising literature together with proper notation regarding each appliance, which material will be exceedingly useful for future reference.

Step 4.-Visit educational exhibits which are frequently made at poultry shows and which are generally staged by Agricultural Experiment Stations and the U.S. Government. Study carefully and take notes on the various lessons taught at these exhibitions. Attend educational lectures which may be given.

Leading Questions.- 1 . How many varieties of fowls were represented at the show studied?

2. What was the number of entries?

3. What was the number of birds shown?

4. Which variety had the greatest entry?

5. Which breeder made the most spectacular winnings?

6. How was the show cooped?

7. How many different firms displayed poultry feeds and appliances?

8. Classify these firms according to product offered.

9 . What poultry papers were on sale in the show room?

10. What was the most striking lesson learned from the educational exhibits studied, and how was it shown? 
Exercise 44 (Continued) 
Exercise 44 (Continued)

THIS BOOK IS DUE ON THE IAST DATE STAMPED BELOW

AN INITIAL FIN OF 25 CENTS WILL BE ASSESSED FOR FAILURE TO RETURN THIS BOOK ON THE DATE DUE. THE PENALTY WILL INCREASE TO 50 CENTS ON THE FOURTH DAY AND TO \$1.00 ON THE SEVENTH DAY OVERDUE.

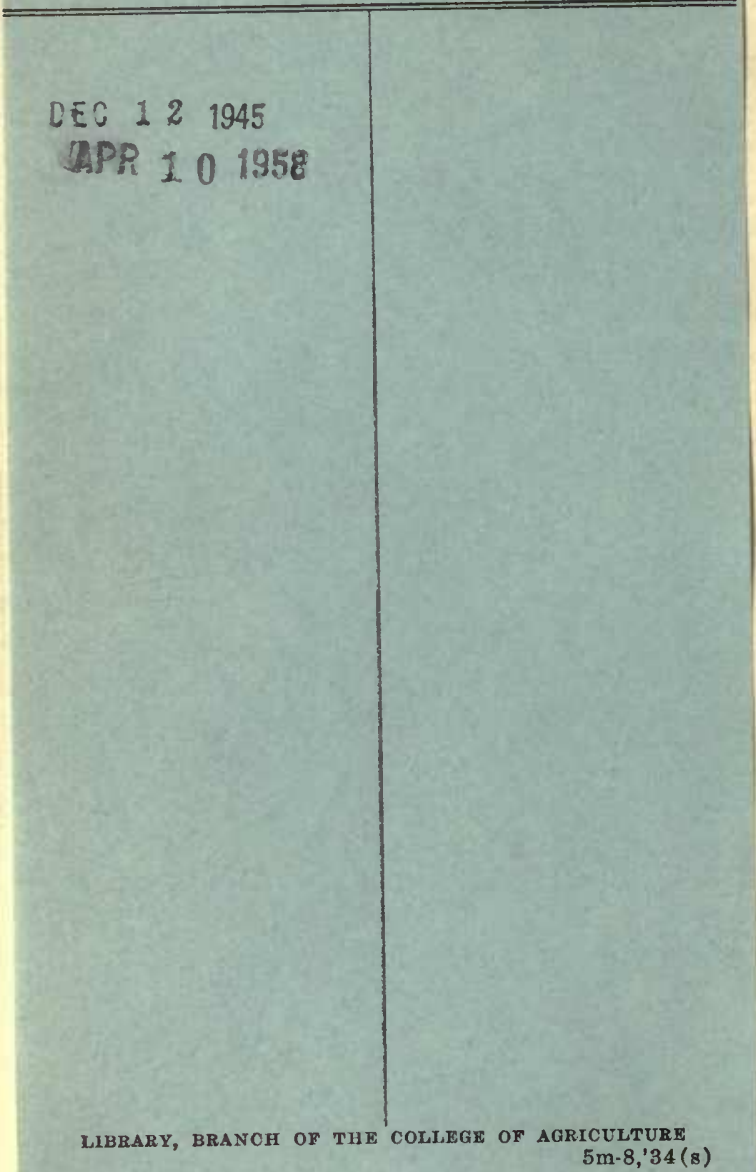


